Provided by the author(s) and University of Galway in accordance with publisher policies. Please cite the published version when available.

\begin{tabular}{|c|c|}
\hline Title & $\begin{array}{l}\text { Comprehensive experimental and simulation study of the } \\
\text { ignition delay time characteristics of binary blended methane, } \\
\text { ethane, and ethylene over a wide range of temperature, } \\
\text { pressure, equivalence ratio, and dilution }\end{array}$ \\
\hline Author(s) & $\begin{array}{l}\text { Baigmohammadi, Mohammadreza; Patel, Vaibhav; Nagaraja, } \\
\text { Shashank; Ramalingam, Ajoy; Martinez, Sergio; Panigrahy, } \\
\text { Snehasish; Mohamed, Ahmed Abd El-Sabor; Somers, Kieran } \\
\text { P.; Burke, Ultan; Heufer, Karl A.; Pekalski, Andrzej; Curran, } \\
\text { Henry J. }\end{array}$ \\
\hline $\begin{array}{c}\text { Publication } \\
\text { Date }\end{array}$ & $2020-06-03$ \\
\hline $\begin{array}{l}\text { Publication } \\
\text { Information }\end{array}$ & $\begin{array}{l}\text { Baigmohammadi, Mohammadreza, Patel, Vaibhav, Nagaraja, } \\
\text { Shashank, Ramalingam, Ajoy, Martinez, Sergio, Panigrahy, } \\
\text { Snehasish, Mohamed, Ahmed Abd El-Sabor, Somers, Kieran } \\
\text { P., Burke, Ultan, Heufer, Karl A., Pekalski, Andrzej, Curran, } \\
\text { Henry J. (2020). Comprehensive Experimental and Simulation } \\
\text { Study of the Ignition Delay Time Characteristics of Binary } \\
\text { Blended Methane, Ethane, and Ethylene over a Wide Range of } \\
\text { Temperature, Pressure, Equivalence Ratio, and Dilution. } \\
\text { Energy \& Fuels, 34(7), 8808-8823. } \\
\text { doi:10.1021/acs.energyfuels.0c00960 }\end{array}$ \\
\hline Publisher & American Chemical Society \\
\hline $\begin{array}{l}\text { Link to } \\
\text { publisher's } \\
\text { version }\end{array}$ & https://doi.org/10.1021/acs.energyfuels.0c00960 \\
\hline Item record & http://hdl.handle.net/10379/16489 \\
\hline DOI & http://dx.doi.org/10.1021/acs.energyfuels.0c00960 \\
\hline
\end{tabular}

Some rights reserved. For more information, please see the item record link above. 


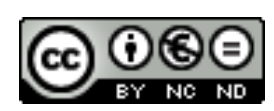




\title{
A Comprehensive Experimental and Simulation Study of the Ignition Delay Time Characteristics of Binary Blended Methane, Ethane, and Ethylene Over a Wide Range of Temperature, Pressure, Equivalence ratio, and Dilution
}

\author{
Mohammadreza Baigmohammadi, ", Vaibhav Patel ${ }^{a}$, Shashank Nagaraja ${ }^{a}$, Ajoy \\ Ramalingam $^{b}$, Sergio Martinez ${ }^{a}$, Snehasish Panigrahy ${ }^{a}$, Ahmed Abd El-Sabor Mohamed ${ }^{a}$, \\ Kieran P. Somers ${ }^{a}$, Ultan Burke ${ }^{a}$, Karl A. Heufer ${ }^{b}$, Andrzej Pekalskic, Henry J. Curran ${ }^{a}$ \\ ${ }^{a}$ Combustion Chemistry Centre, School of Chemistry, Ryan Institute, National University of Ireland Galway, University \\ Road, Galway, H91 TK33, Ireland
}

${ }^{b}$ Physico-Chemical Fundamentals of Combustion, RWTH Aachen University, 52056 Aachen, Germany

'Shell research limited, Shell Centre London, London SE1 7NA, United Kingdom

*Corresponding author: mohammadreza.baigmohammadi@nuigalway.ie

\begin{abstract}
A comprehensive experimental and kinetic modelling study of the ignition delay time (IDT) characteristics of some binary-blends of $\mathrm{C}_{1}-\mathrm{C}_{2}$ gaseous hydrocarbons such as methane/ethylene, methane/ethane, and ethane/ethylene were performed over a wide range of composition $(90 \% / 10 \%, 70 \% / 30 \%, 50 \% / 50 \%)$, temperature ( $\sim 800-2000 \mathrm{~K})$, pressure ( 1-40 bar), equivalence ratio $(\sim 0.5-2.0)$, and dilution $(\sim 75-90 \%)$. An extensive literature review was conducted, and available data were extracted to create a comprehensive database for our simulations. Based on existing literature data, an experimental matrix was designed using the Taguchi approach $\left(\mathrm{L}_{9}\right)$ in order to identify and complete the experimental matrix required to generate a comprehensive experimental IDT set necessary for the validation of a chemical kinetic model. The required high- and low-temperature IDTs were collected using low/high-pressure shock tubes and rapid compression machines, respectively. The predictions of NUIGMech1.0 are examined versus all of the available experimental data, including those taken in the current study using the IDT simulations and a correlation technique. Moreover, the individual effect of the studied parameters, including mixture composition, pressure, equivalence ratio, and dilution on IDT is investigated over the studied temperature range. Correlations that were developed based on NUIGMech1.0 are presented for each specific blended fuel over the conditions studied. These correlations show an acceptable performance versus the experimental data.
\end{abstract}

Keywords: methane, ethane, ethylene, shock tube, RCM, ignition delay time 


\section{Introduction}

Explaining the pyrolysis and/or oxidation processes of heavy and complex hydrocarbon fuels depends on the development of high-fidelity chemical mechanisms. In this regard, understanding the pyrolysis and/or oxidation processes of small $\left(\mathrm{C}_{1}-\mathrm{C}_{2}\right)$ hydrocarbons are important because of their crucial role in kinetic behavior at the end chain of the pyrolysis and/or oxidation processes of larger hydrocarbons. Therefore, developing a high-fidelity chemical mechanism that can precisely explain the pyrolysis and/or oxidation processes of small hydrocarbons is very desirable in terms of explaining conditions relevant to industrial burners, gas turbines, and internal combustion engines. Ignition delay time (IDT) is a criterion extensively used to validate chemical mechanisms, and it is often used for comparing various chemical mechanisms and developing new ones. To do so, a comprehensive IDT database is required as a prerequisite so that mechanisms can be tested and validated. Therefore, an extensive literature review was performed, and available IDTs for binary-fuel mixtures of methane/ethylene ${ }^{1}$, methane/ethane $\mathrm{e}^{2-11}$, and ethane/ethylene were extracted and stored, as shown in Figure 1. It can be seen that, although there is sufficient IDT data in the literature for methane/ethane (alkane-alkane) mixtures, there is no comprehensive data for alkane/alkene mixtures including methane/ethylene and ethane/ethylene over a wide range of pressures, temperatures, equivalence ratios, and dilution (squares in Figure 1). Therefore, new experimental tests were defined for targeted binary-fuel mixtures (alkane/alkene) $+\mathrm{O}_{2}+\mathrm{N}_{2}+\mathrm{Ar}$ (spheres in Figure 1) to encapsulate a wide range of temperature, pressure, equivalence ratio, alkane ratio, and dilution.

(a)

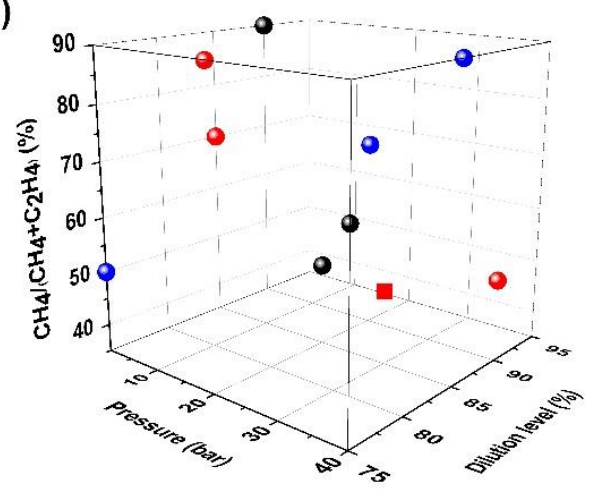

(b)

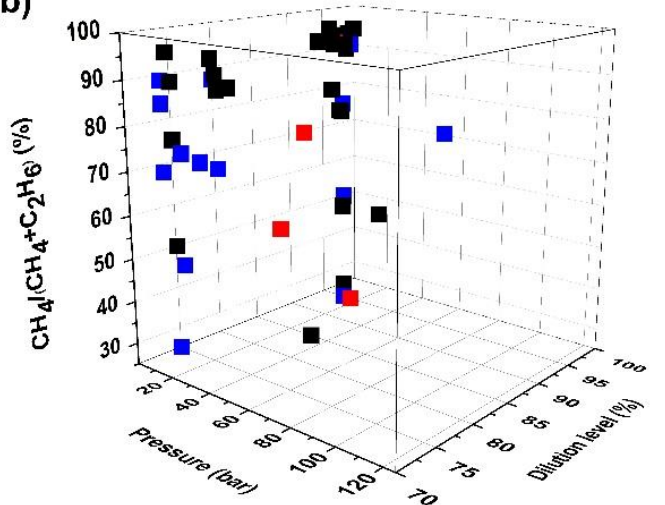

(c)

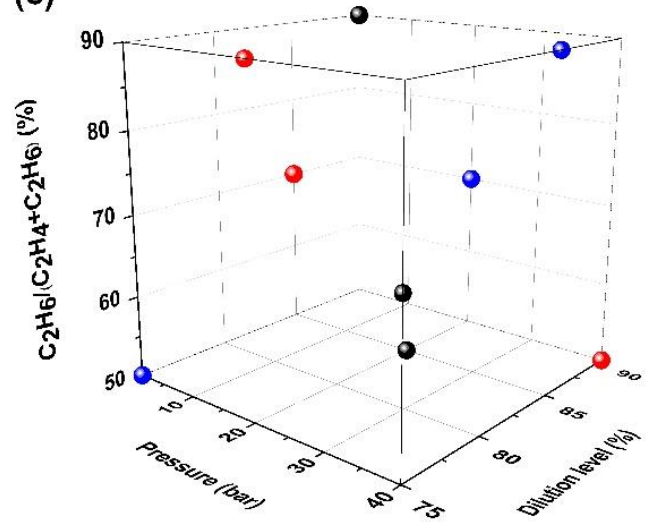

- Available; fuel-lean

- Present study; fuel-lean

- Available; stoichiometric

- Present study; stoichiometric

- Available; fuel-rich

- Present study; fuel-rich

Figure 1. Extracted data from the studied literature (squares); new experimental tests defined in the current study (spheres); Blue-spheres/squares: fuel-lean mixtures; Black-spheres/squares: stoichiometric mixtures; Red-spheres/squares: fuel-rich mixtures. 
It is believed that conducting the required experiments under the compressed pressure range of $\sim 1-40$ bar and also the compressed temperature range of $\sim 800-2000 \mathrm{~K}$ from fuel-lean to fuel-rich conditions and at different levels of dilution, and with different alkene concentrations may disclose data which could not be interpreted from the available literature. Thus, we aim to present a comprehensive chemical mechanism that can precisely reproduce the experimental IDTs of various binary-fuel $\mathrm{C}_{1}-\mathrm{C}_{2}$ mixtures over a wide range of operating conditions. In the present study, the Taguchi $\left(\mathrm{DOE}^{1}\right)$ method was applied to optimize the number of required experiments.

\section{Design of experiments and experimental approach}

The experiments were designed using an $\mathrm{L}_{9}$ Taguchi matrix ${ }^{12}$ for four parameters of ethylene concentration, pressure, equivalence ratio, and dilution. This approach is analogous to previous work by Baigmohammadi et al. ${ }^{13}$, and details can be found there. In this current study, alkanes (methane and ethane) are the abundant components, so that the presence of the alkene (ethylene) in a mixture is defined as: $\left[1-\left(\frac{\text { mole fraction }\left.\right|_{\text {Alkane }}}{\text { mole fraction }\left.\right|_{\text {Fuel }}}\right)\right] \times 100 \%$, which is varied from $10-50 \%$. Also, the diluents $\left(\mathrm{N}_{2}\right.$ and $\left.\mathrm{Ar}\right)$ concentrations are varied from $75 \%$ to $90 \%$ of the reactive mixtures. Three equivalence ratios, $0.5,1.0$, and 2.0, and three compressed mixture pressures $\left(p_{5}, p_{\mathrm{C}}\right)$, namely 1, 20, and 40 were selected to cover the proposed cubes presented in Figures 1(a) and (c). Besides, the compressed temperature $\left(T_{5}, T_{\mathrm{C}}\right)$ range was varied from $\sim 800-2000 \mathrm{~K}$ based on the defined cases and the viability of the applied instruments in measuring IDTs with acceptable accuracy.

Mixture IDTs of the defined mixtures and conditions presented in Table 1 were measured using low/high-pressure shock tubes (L/HPST) and rapid compression machines (RCMs) all at NUI Galway in the low- and high-temperature regimes, respectively. However, some low-temperature IDTs (RCM; P8C3,4,8 in Table 1) were measured in collaboration with the Physico-Chemical Fundamentals of Combustion (PCFC) group of RWTH Aachen University to increase the fidelity of the database and to ensure that they are facility independent. The physical performance of the facilities are well known and have been extensively discussed previously ${ }^{5,10,14-19}$. However, a summary of the facility characteristics and exemplary pressure traces are provided as Supplementary material (Sections 2-6).

As seen in Figure 1(b), sufficient available IDT data exists in the literature for methane/ethane mixtures precluding the need for more experiments. As presented in Table 1, a unique code has been assigned to each experiment. It should be noted that the presented data in this paper is a part of a larger project ( 3 of 12; phases (P): 5, 6, and 8) so that, for better handling of the data, we have been using a common description for the applied mixtures and conditions throughout the papers. In this regard, "Px" refers to the fuel blends, which is "P5: methane/ethylene", "P6: methane/ethane", and "P8: ethane/ethylene", respectively. Also, the "C" notation refers to the studied conditions, which change from 1 to 9 in accordance with changes in fuel composition, pressure, equivalence ratio, and dilution.

${ }^{1}$ Design of experiments 
Table 1. Test conditions defined in the current study.

\begin{tabular}{|c|c|c|c|c|c|c|c|c|c|c|}
\hline \multirow{2}{*}{ No } & \multirow{2}{*}{ Code } & \multicolumn{5}{|c|}{ Mixture composition (mole fraction) } & \multirow[b]{2}{*}{$\varphi$} & \multirow{2}{*}{$T(\mathbf{K})$} & \multirow{2}{*}{$p$ (bar) } & \multirow{2}{*}{ Ref. } \\
\hline & & $\mathrm{CH}_{4}$ & $\mathrm{C}_{2} \mathrm{H}_{4}$ & $\mathrm{C}_{2} \mathrm{H}_{6}$ & $\mathbf{O}_{2}$ & $\mathbf{N}_{2}+\mathbf{A r}$ & & & & \\
\hline 1 & P5C1 & 0.02083 & 0.02083 & 0 & 0.2083 & $0.75+0.0$ & 0.5 & $1167-2024$ & 1 & \multirow{9}{*}{$\begin{array}{c}\text { This study: } \\
\text { NUIG ST and RCM }\end{array}$} \\
\hline 2 & $\mathrm{P} 5 \mathrm{C} 2$ & 0.02143 & 0.02143 & 0 & 0.1071 & 0.85 & 1.0 & $923-1546$ & 20 & \\
\hline 3 & P5C3 & 0.0222 & 0.0222 & 0 & 0.0555 & 0.90 & 2.0 & 869-1745 & 40 & \\
\hline 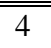 & P5C4 & 0.05303 & 0.02273 & 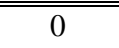 & 0.17424 & 0.75 & 1.0 & 845-1465 & 40 & \\
\hline 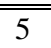 & P5C5 & 0.0488 & 0.0209 & 0 & 0.0802 & $0.75+0.10$ & 2.0 & 1471-2022 & 1 & \\
\hline 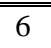 & P5C6 & 0.0125 & 0.0054 & 0 & 0.082 & 0.90 & 0.5 & 995-1783 & 20 & \\
\hline 7 & P5C7 & 0.10976 & 0.0122 & 0 & 0.12805 & 0.75 & 2.0 & 947-1840 & 20 & \\
\hline 8 & P5C8 & 0.02596 & 0.00288 & 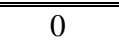 & 0.12115 & 0.85 & 0.5 & "921-1738 & 40 & \\
\hline 9 & P5C9 & 0.029 & 0.0032 & 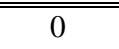 & 0.0677 & $0.75+0.15$ & $\begin{array}{c}1.0 \\
\end{array}$ & "1570-2082 & 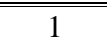 & \\
\hline 10 & P6C1 & 0.0015 & 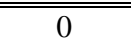 & 0.0015 & "0.0017 & $0.0+0.98$ & 0.5 & "1248-1571 & 1.46 & \multirow{5}{*}{ Aul et al. ${ }^{2}$} \\
\hline 11 & P6C2 & 0.0067 & 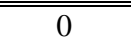 & 0.0067 & (0.0367 & $0.0+0.95$ & 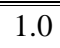 & "1190-1377 & 32.02 & \\
\hline 12 & $\begin{array}{l}\text { P6C3 } \\
\end{array}$ & 0.0316 & 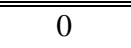 & 0.0316 & (20.0868 & $0.0+0.85$ & 2.0 & "1094-1366 & 15.44 & \\
\hline 13 & P6C4 & 0.0091 & 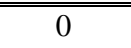 & 0.0273 & 0.1136 & $0.0+0.85$ & 1.0 & "1166-1266 & 31.42 & \\
\hline 14 & P6C5 & 0.0514 & 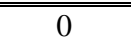 & 0.0171 & 0.0814 & $0.0+0.85$ & 2.0 & "1143-1513 & 29.03 & \\
\hline \multirow[b]{2}{*}{15} & \multirow{2}{*}{ P6C6 } & \multirow{2}{*}{0.0228} & \multirow{2}{*}{0} & \multirow{2}{*}{0.0123} & \multirow{2}{*}{0.2015} & \multirow{2}{*}{$0.7574+0.0$} & 0.5 & "1091-1437 & 22.26 & "Petersen et al. ${ }^{8}$ \\
\hline & & & & & & & 0.6 & $848-883$ & 9.62 & Beerer and McDonell ${ }^{3}$ \\
\hline 16 & P6C7 & 0.0419 & 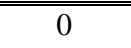 & 0.0047 & 0.2003 & 0.7531+0.0 & 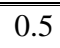 & (1155-1532 & 22.71 & Petersen et al. ${ }^{8}$ \\
\hline \multirow{2}{*}{17} & \multirow{2}{*}{$\mathrm{P} 6 \mathrm{C} 8$} & 0.0801 & 0 & 0.0089 & 0.1913 & $0.7197+0.0$ & \multirow{2}{*}{1.0} & $911-1221$ & \multirow{2}{*}{40} & Huang and Bushe ${ }^{7}$ \\
\hline & & 0.0766 & 0 & 0.0085 & 0.1830 & $0.3+0.432$ & & $909-1038$ & & Gersen et al. ${ }^{9}$ \\
\hline 18 & P6C9 & 0.0012 & 0 & 0.0036 & 0.0152 & $0.0+0.98$ & 1.0 & 1324-1700 & 1.36 & Aul et al. ${ }^{2}$ \\
\hline 19 & P8C1 & 0 & 0.0167 & 0.0167 & 0.2167 & $0.75+0.0$ & 0.5 & 1153-1862 & 1 & This study: \\
\hline 20 & P8C2 & 0 & 0.01765 & 0.01765 & 0.11471 & 0.85 & 1.0 & 901-1452 & 20 & NUIG ST and RCM \\
\hline 21 & $\mathrm{P} 8 \mathrm{C} 3$ & 0 & 0.0190 & 0.0190 & 0.0619 & 0.90 & 2.0 & $892-1540$ & 40 & $\begin{array}{c}\text { This study: } \\
\text { NUIG (ST) \& RWTH } \\
\text { Aachen }^{2} \text { (RCM) }\end{array}$ \\
\hline \multirow{2}{*}{22} & \multirow{2}{*}{$\mathrm{P} 8 \mathrm{C} 4$} & \multirow{2}{*}{0} & \multirow{2}{*}{0.01724} & \multirow{2}{*}{0.04023} & \multirow{2}{*}{0.19253} & \multirow{2}{*}{0.75} & \multirow{2}{*}{1.0} & $1106-1411$ & 40 & $\begin{array}{l}\text { This study: } \\
\text { NUIG (ST) }\end{array}$ \\
\hline & & & & & & & & $902-971$ & 30 & $\begin{array}{c}\text { This study: } \\
\text { RWTH Aachen (RCM) }\end{array}$ \\
\hline 23 & P8C5 & 0 & 0.0168 & 0.0392 & 0.0939 & $0.75+0.10$ & 2.0 & 1252-1870 & 1 & \\
\hline 24 & P8C6 & 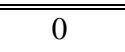 & 0.0039 & $\begin{array}{c}0.0091 \\
\end{array}$ & 0.087 & 0.90 & 0.5 & "958-1503 & 20 & \\
\hline 25 & P8C7 & 0 & 0.0092 & 0.0826 & 0.1583 & 0.75 & 2.0 & $8992-1520$ & 20 & \\
\hline 26 & P8C8 & 0 & 0.0019 & 0.0171 & 0.1310 & 0.85 & 0.5 & $933-1446$ & 40 & $\begin{array}{c}\text { This study: } \\
\text { NUIG (ST) \& RWTH } \\
\text { Aachen (RCM) }\end{array}$ \\
\hline 27 & P8C9 & 0 & 0.0022 & 0.0202 & 0.0775 & $0.75+0.15$ & 1.0 & "1250-1930 & 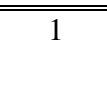 & $\begin{array}{l}\text { This study: } \\
\text { NUIG (ST) }\end{array}$ \\
\hline
\end{tabular}

\footnotetext{
${ }^{2}$ Experimental data is measured for the current study at PCFC of RWTH Aachen University.
} 


\subsection{Set-up and procedure}

The current study is categorized into six different stages; 1 : an extensive literature review; 2 : database development; 3: simulating the available literature data using NUIGMech1.0; 4: defining new experimental tests using an $\mathrm{L}_{9}$ Taguchi matrix; 5: conducting the RCM and L/HPST experiments; 6: modelling the new experimental results with NUIGMech1.0. To make the study more concise, comprehensive Supplementary material files ${ }^{3}$ are provided in support of the data presented in the main manuscript. The supplementary files include non-reactive RCM traces, the original spreadsheets of the experimental tests, L/HPST oscilloscope traces, and the combined figures of reactive, non-reactive, and simulation pressure traces. Furthermore, all of the general information related to the applied gases (fuel/oxygen/argon/nitrogen), the applied facilities, and data acquisition systems to collect the IDTs are provided as Supplementary material.

\subsection{Uncertainty analysis}

To increase the fidelity of the results, a comprehensive uncertainty analysis was conducted using the data taken in both our L/HPST and RCM and is briefly discussed here. The uncertainty analysis was developed based on studies conducted by Petersen et al. ${ }^{20}$ and Weber et al. ${ }^{21}$. In this regard, the average uncertainties in the compressed mixture temperatures $\left(T_{\mathrm{C}}\right.$ or $\left.T_{5}\right)$ and measured IDTs in STs and RCM are summarized in Table 2. Details of this analysis are provided as Supplementary material (Section 7).

Table 2. Average uncertainties for compressed mixture temperature $\left(T_{\mathrm{C}}\right.$ or $\left.T_{5}\right)$ and measured IDTs.

\begin{tabular}{|c|c|c|}
\hline Facility & $\boldsymbol{\sigma}_{\boldsymbol{T}_{\mathrm{C}, 5}}(\mathbf{K})$ & $\boldsymbol{\sigma}_{\boldsymbol{I D T} \boldsymbol{T}}(\boldsymbol{\%})$ \\
\hline NUIG-L/HPST & $\pm 30 / 20$ & \pm 25 \\
\hline NUIG-RCM & \pm 10 & \pm 20 \\
\cline { 1 - 2 } PCFC-RCM $^{10}$ & \pm 5 & \\
\hline
\end{tabular}

According to the literature ${ }^{20,22,23}$, and also the conditions studied here, values of $\pm 30 / 20 \mathrm{~K}$ (L/HPST), $\pm 5-15 \mathrm{~K}(\mathrm{RCM})$, and $\pm 25 \%$ (L/HPST) and 20\% (RCM) are estimated as the average uncertainties for both the end of compression temperature $\left(T_{\mathrm{C}}\right)$ and the measured IDTs, respectively.

\section{Computational modelling}

Simulations were conducted using NUIGMech1.0 to simulate the experimental targets. This is a modified version of NUIGMech $0.9^{13}$ for higher hydrocarbons up to $\mathrm{C}_{8}$ and aromatics. In this regard, the experimental data were simulated using a Python script based on the CANTERA ${ }^{24}$ library (ST simulations) and also CHEMKIN-Pro $18.2^{25}$ software (RCM simulations). As already comprehensively discussed in the literature ${ }^{22,23}$, although the simulations in the ST operating regimes are performed using the constant volume reactor model, the RCM simulations are performed using the effective volume approach by

\footnotetext{
${ }^{3}$ The supporting/supplementary information/data/files are referred using "S" notation.
} 
imposing a heat loss boundary condition on the calculations due to facility effects, including heat losses, during compression and in the post-compression zone of the reaction chamber ${ }^{10,14,26}$.

\section{Results and discussions}

All experimental results related to the studied conditions in Table 1, whether taken from the literature or from the present study, are presented in the following figures in accordance to the applied fuels (methane/ethylene, methane/ethane, and ethane/ethylene) and the wide range of operating conditions examined.

\subsection{General performance of the NUIG mechanism and the correlations versus experimental data}

The performance of NUIGMech1.0 versus all experimental available IDT data is shown in Figures 24. The symbols refer to the experimental data; however, the square symbols with a cross through them demonstrate experimental data affected by pre-ignition or facility effects. The solid black line refers to NUIGMech1.0 predictions.

Figures 2-4 show that NUIGMech1.0 predicts the methane/ethylene, methane/ethane, and ethane/ethylene binary-fuel blend IDT measurements very well over the wide range of conditions studied ( $\varphi$ : 0.5-2.0, T: 830-2100 K, $p:$ 1-40 bar, 9 different compositions, and dilution: 75-90\%). However, there is a deviation between the simulations and experimental data in Figures 3(h) and 4(d). Figure 4(d) illustrates that the experimental data are affected by the facility's boundary conditions in the temperature range $900-1050 \mathrm{~K}$ at $p=40 \mathrm{bar}$. These data suffer from pre-ignition events that occur behind the reflected shock in the NUIG-HPST. This pre-ignition was observed even on cleaning the shock tube after each experiment. The same phenomenon occurred for the same mixture at 40 bar in the low-temperature regime in the PCFC-RCM. In both cases, pre-ignition appeared as a gradual increase in pressure before the main ignition, shortening the overall IDT. In the case of the RCM, some deposits have been observed on the reactor endwall, which may induce the pre-ignition. However, these deposits were only present for the 40 bar experiments so that they and related pre-ignitions were suppressed by reducing the compressed pressure to 30 bar. Similarly, it might be inferred that the experimental data presented in Figure 3(h) (Figure S34) may suffer from a kind of pre-ignition (specifically in ${ }^{9}$ due to the very short reported IDTs of $<3$ $\mathrm{ms}$ ) in the intermediate-to-low temperature regime in ${ }^{7}$ and at $1000-1050 \mathrm{~K} \mathrm{in}^{9}$. Comparing the conditions presented in Figures 3(h) and 4(d), it is interesting to note that ethane is the common fuel component in the mixtures, and the common conditions are 40 bar and $75 \%$ dilution. Therefore, it may be concluded that this undesirable effect stems from the presence of ethane in the blends at $40 \mathrm{bar}$ and at fuel/air conditions ( $71-75 \%$ dilution). Although it is known that ethylene and ethane are more reactive fuels compared to methane, the individual effect and portion of each studied parameter on the reactivity of the mixtures cannot be understood directly from Figures $2-4$ as too many parameters, e.g. binary fuel combination, pressure, equivalence ratio, and dilution, are all changing at once. Thus, the individual and combined effects of the studied parameters on IDTs of the studied methane/ethylene and ethane/ethylene mixtures are considered below. 
Furthermore, comprehensive comparisons of IDT, laminar burning velocities (LBVs), and speciation plots shown in the Supporting information file (Figures S26-38 in Section 9) demonstrate that NUIGMech1.0 can not only accurately predict the experimental IDTs studied, but it can also reasonably anticipate experimental LBVs and speciation data taken from the literature in comparison to the available chemical mechanisms (Table S11).
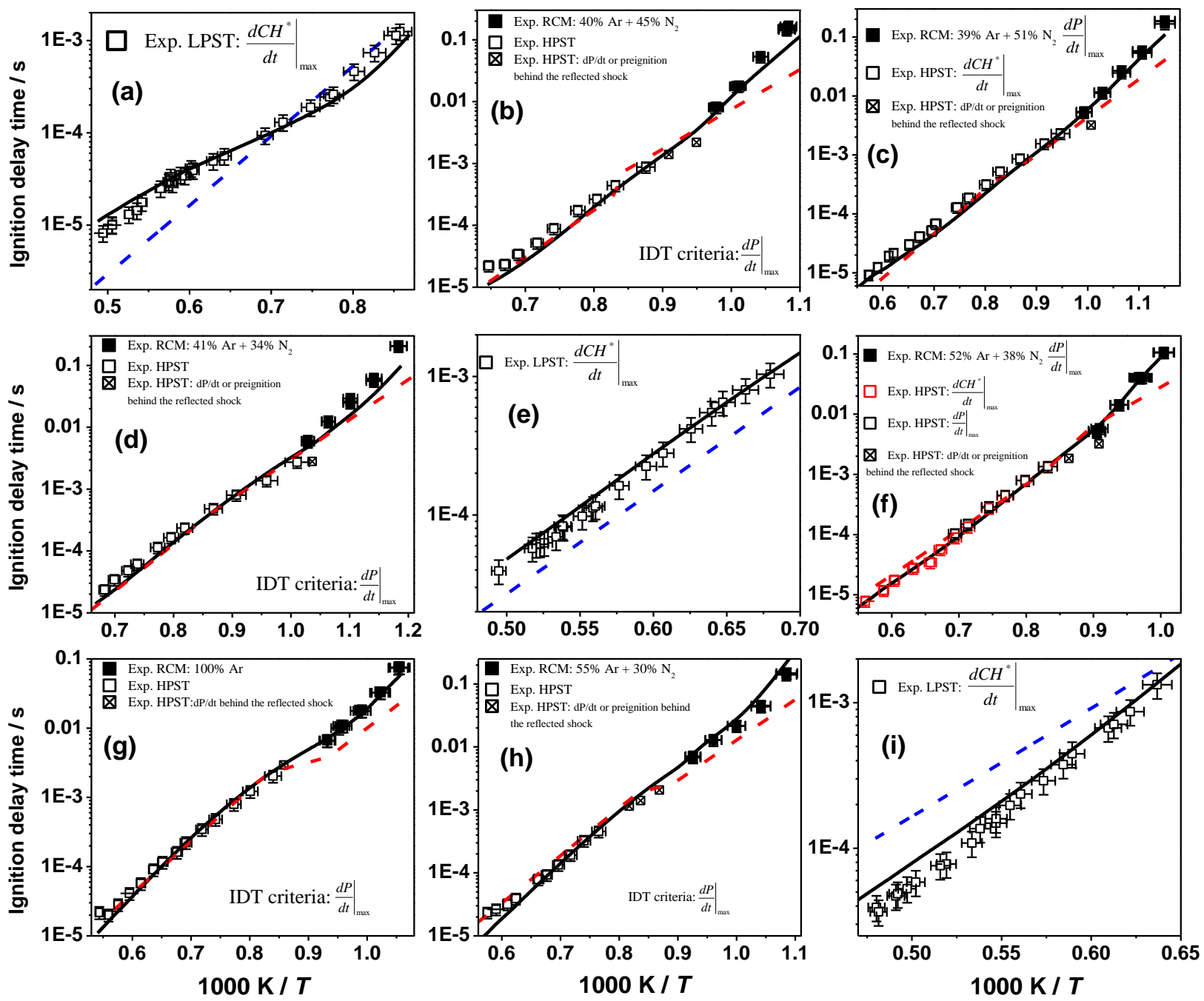

Figure 2. Experimental and simulation data of methane/ethylene's IDT values: (a) $2.08 \% \mathrm{CH}_{4}, 2.08 \%$ $\mathrm{C}_{2} \mathrm{H}_{4}, 20.83 \% \mathrm{O}_{2},(\varphi=0.5)$ in $75 \% \mathrm{~N}_{2}$ at $\bar{p}_{\mathrm{C}}=1$ bar, $\mathrm{P} 5 \mathrm{Cl}$; (b) $2.143 \% \mathrm{CH}_{4}, 2.143 \% \mathrm{C}_{2} \mathrm{H}_{4}, 10.71 \% \mathrm{O}_{2},(\varphi$ $=1.0)$ in $75 \% \mathrm{~N}_{2}, 10 \% \mathrm{Ar}, \bar{p}_{\mathrm{C}}=20$ bar, $\mathrm{P} 5 \mathrm{C} 2$; (c) $2.22 \% \mathrm{CH}_{4}, 2.22 \% \mathrm{C}_{2} \mathrm{H}_{4}, 5.55 \% \mathrm{O}_{2},(\varphi=2.0)$ in $75 \%$ $\mathrm{N}_{2}, 15 \% \mathrm{Ar}, \bar{p}_{\mathrm{C}}=40$ bar, P5C3; (d) $5.303 \% \mathrm{CH}_{4}, 2.273 \% \mathrm{C}_{2} \mathrm{H}_{4}, 17.424 \% \mathrm{O}_{2},(\varphi=1.0)$ in $75 \% \mathrm{~N}_{2}, \bar{p}_{\mathrm{C}}=$ 40 bar, P5C4; (e) $4.88 \% \mathrm{CH}_{4}, 2.09 \% \mathrm{C}_{2} \mathrm{H}_{4}, 8.02 \% \mathrm{O}_{2},(\varphi=2.0)$ in $75 \% \mathrm{~N}_{2}, 10 \% \mathrm{Ar}, \bar{p}_{\mathrm{C}}=1$ bar, P5C5; (f) $1.25 \% \mathrm{CH}_{4}, 0.54 \% \mathrm{C}_{2} \mathrm{H}_{4}, 8.2 \% \mathrm{O}_{2}(\varphi=0.5)$ in $75 \% \mathrm{~N}_{2}, 15 \%$ Ar at $\bar{p}_{\mathrm{C}}=20$ bar, P5C6; $(\mathrm{g}) 10.976 \% \mathrm{CH}_{4}$, $1.22 \% \mathrm{C}_{2} \mathrm{H}_{4}, 12.805 \% \mathrm{O}_{2},(\varphi=2.0)$ in $75 \% \mathrm{~N}_{2}, \bar{p}_{\mathrm{C}}=20$ bar, $\mathrm{P} 5 \mathrm{C} 7$; (h) $2.596 \% \mathrm{CH}_{4}, 0.288 \% \mathrm{C}_{2} \mathrm{H}_{4}, 12.115 \%$ $\mathrm{O}_{2}(\varphi=0.5)$ in $75 \% \mathrm{~N}_{2}, 10 \%$ Ar at $\bar{p}_{\mathrm{C}}=40$ bar, P5C8; (i) $2.9 \% \mathrm{CH}_{4}, 0.32 \% \mathrm{C}_{2} \mathrm{H}_{4}, 6.77 \% \mathrm{O}_{2},(\varphi=2.0)$ in $75 \% \mathrm{~N}_{2}, 15 \% \mathrm{Ar}, \bar{p}_{\mathrm{C}}=1$ bar, P5C9. (solid-line: NUIGMech1.0, dash-line: derived correlations (section 4.3)) 

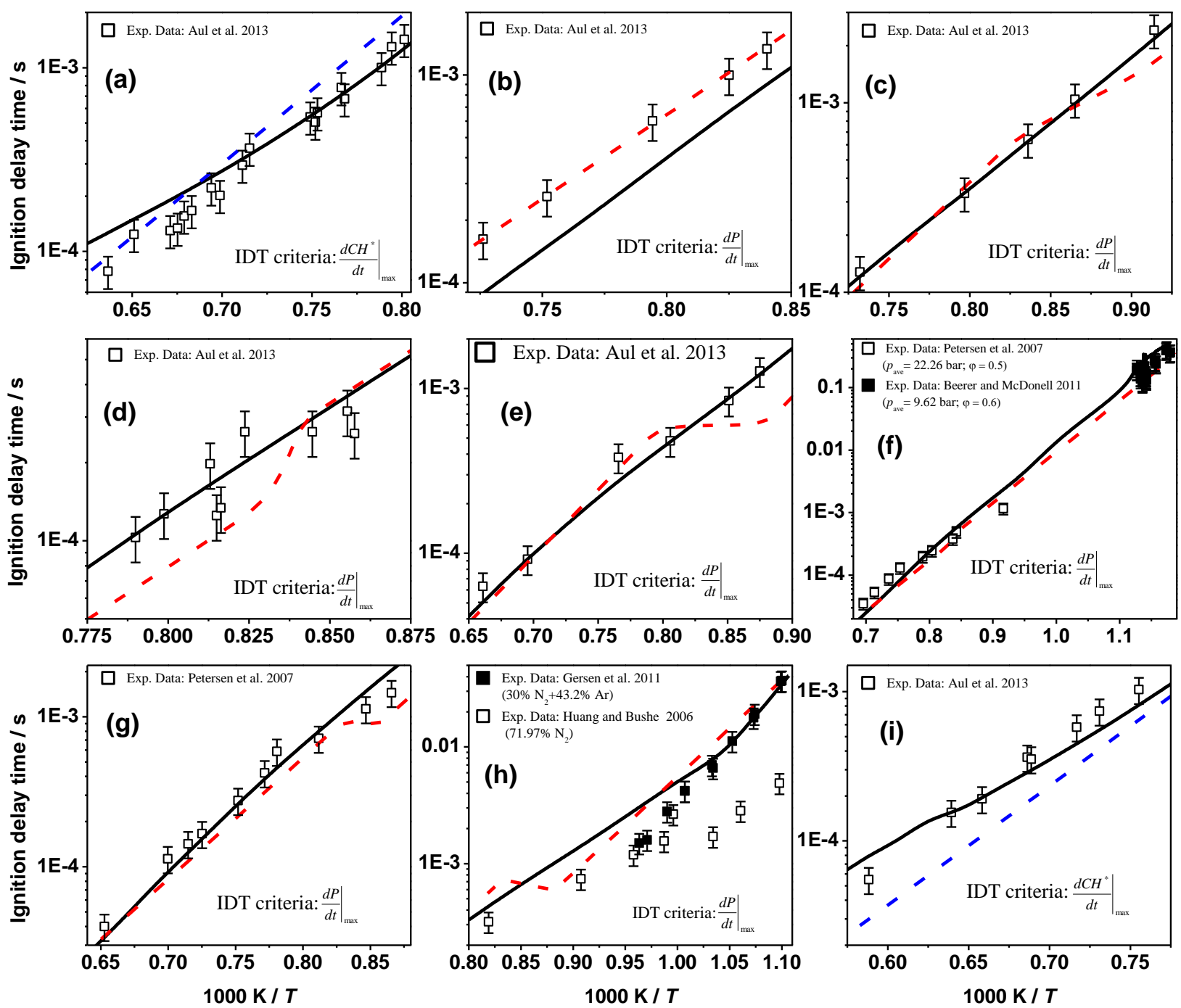

Figure 3. Available experimental and simulated data of methane/ethane's IDT values at: (a) $0.15 \% \mathrm{CH}_{4}$, $0.15 \% \mathrm{C}_{2} \mathrm{H}_{6}, 1.7 \% \mathrm{O}_{2},(\varphi=0.5)$ in $98 \% \mathrm{Ar}, \bar{p}_{\mathrm{C}}=1.46$ bar, $\mathrm{P} 6 \mathrm{C} 1$; (b) $0.67 \% \mathrm{CH}_{4}, 0.67 \% \mathrm{C}_{2} \mathrm{H}_{6}, 3.67 \% \mathrm{O}_{2}$, $(\varphi=1.0)$ in $95 \% \mathrm{Ar}, \bar{p}_{\mathrm{C}}=32.02$ bar, $\mathrm{P} 6 \mathrm{C} 2$; (c) $3.16 \% \mathrm{CH}_{4}, 3.16 \% \mathrm{C}_{2} \mathrm{H}_{6}, 8.68 \% \mathrm{O}_{2},(\varphi=2.0)$ in $85 \% \mathrm{Ar}$, $\bar{p}_{\mathrm{C}}=15.44$ bar, $\mathrm{P} 6 \mathrm{C} 3$; (d) $0.91 \% \mathrm{CH}_{4}, 2.73 \% \mathrm{C}_{2} \mathrm{H}_{6}, 11.36 \% \mathrm{O}_{2},(\varphi=1.0)$ and $85 \% \mathrm{Ar}, \bar{p}_{\mathrm{C}}=31.42 \mathrm{bar}$, P6C4; (e) $5.14 \% \mathrm{CH}_{4}, 1.71 \% \mathrm{C}_{2} \mathrm{H}_{6}, 8.14 \% \mathrm{O}_{2},(\varphi=2.0)$ in $85 \% \mathrm{Ar}, \bar{p}_{\mathrm{C}}=29.03$ bar, P6C5; (f) $2.28 \% \mathrm{CH}_{4}$, $1.23 \% \mathrm{C}_{2} \mathrm{H}_{6}, 20.15 \% \mathrm{O}_{2},\left(\varphi=0.5^{8}\right.$ and $\left.0.6^{3}\right)$ in $75.74 \% \mathrm{~N}_{2}, \bar{p}_{\mathrm{C}}=22.26$ bar $^{8}$ and 9.62 bar $^{3}$, P5C6; $(\mathrm{g})$ $4.19 \% \mathrm{CH}_{4}, 0.47 \% \mathrm{C}_{2} \mathrm{H}_{6}, 20.03 \% \mathrm{O}_{2},(\varphi=0.5)$ in $75.31 \% \mathrm{~N}_{2}, \bar{p}_{\mathrm{C}}=22.71 \mathrm{bar}, \mathrm{P} 5 \mathrm{C} 7$; (h) $8.01 \%{ }^{7} / 7.66 \%{ }^{9}$ $\mathrm{CH}_{4}, 0.89 \%{ }^{7} / 0.85 \%{ }^{9} \mathrm{C}_{2} \mathrm{H}_{6}, 19.13 \%{ }^{7} / 18.3 \%{ }^{9} \mathrm{O}_{2},(\varphi=1.0)$ in $71.97 \% \mathrm{~N}_{2}{ }^{7} / 30 \% \mathrm{~N}_{2}+43.2 \% \mathrm{Ar}^{9}, \bar{p}_{\mathrm{C}}=40$ bar; P6C8; (i) $0.12 \% \mathrm{CH}_{4}, 0.36 \% \mathrm{C}_{2} \mathrm{H}_{6}, 1.52 \% \mathrm{O}_{2},(\varphi=1.0)$ and $98 \% \mathrm{Ar}, \bar{p}_{\mathrm{C}}=1.36$ bar, P6C9. (solid-line: NUIGMech1.0, dash-line: derived correlations (section 4.3)) 

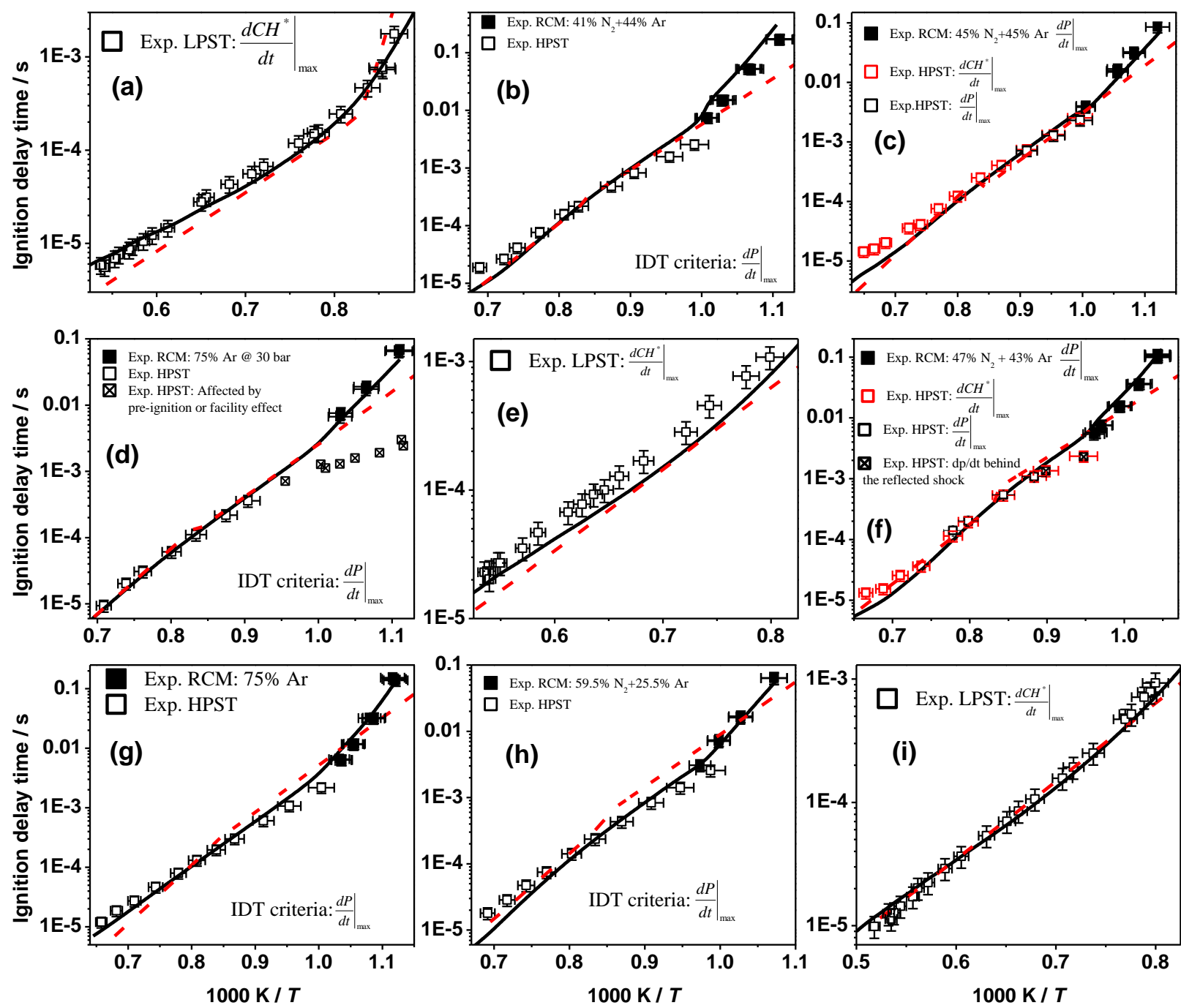

Figure 4. Experimental and simulation data for ethane/ethylene oxidation at: (a) $1.67 \% \mathrm{C}_{2} \mathrm{H}_{6}, 1.67 \% \mathrm{C}_{2} \mathrm{H}_{4}$, $21.67 \% \mathrm{O}_{2}(\varphi=0.5), 75 \% \mathrm{~N}_{2}, \bar{p}_{\mathrm{C}}=1$ bar, $\mathrm{P} 8 \mathrm{Cl}$; (b) $1.765 \% \mathrm{C}_{2} \mathrm{H}_{6}, 1.765 \% \mathrm{C}_{2} \mathrm{H}_{4}, 11.471 \% \mathrm{O}_{2}(\varphi=1.0)$, $75 \% \mathrm{~N}_{2}, 10 \% \mathrm{Ar}, \bar{p}_{\mathrm{C}}=20$ bar, $\mathrm{P} 8 \mathrm{C} 2$; (c) $1.9 \% \mathrm{C}_{2} \mathrm{H}_{6}, 1.9 \% \mathrm{C}_{2} \mathrm{H}_{4}, 6.19 \% \mathrm{O}_{2}(\varphi=2.0), 75 \% \mathrm{~N}_{2}, 15 \% \mathrm{Ar}$, $\bar{p}_{\mathrm{C}}=40$ bar, P8C3; (d) $4.023 \% \mathrm{C}_{2} \mathrm{H}_{6}, 1.724 \% \mathrm{C}_{2} \mathrm{H}_{4}, 19.253 \% \mathrm{O}_{2}(\varphi=1.0), 75 \% \mathrm{~N}_{2}, \bar{p}_{\mathrm{C}}=40$ bar, P8C4; (e) $3.92 \% \mathrm{C}_{2} \mathrm{H}_{6}, 1.68 \% \mathrm{C}_{2} \mathrm{H}_{4}, 9.39 \% \mathrm{O}_{2}(\varphi=2.0), 75 \% \mathrm{~N}_{2}, 10 \% \mathrm{Ar}, \bar{p}_{\mathrm{C}}=1$ bar, P8C5; (f) $0.91 \% \mathrm{C}_{2} \mathrm{H}_{6}$, $0.39 \% \mathrm{C}_{2} \mathrm{H}_{4}, 8.7 \% \mathrm{O}_{2}(\varphi=0.5), 75 \% \mathrm{~N}_{2}, 15 \% \mathrm{Ar}, \bar{p}_{\mathrm{C}}=20$ bar, P8C6; $(\mathrm{g}) 8.26 \% \mathrm{C}_{2} \mathrm{H}_{6}, 0.92 \% \mathrm{C}_{2} \mathrm{H}_{4}$, $15.83 \% \mathrm{O}_{2}(\varphi=2.0), 75 \% \mathrm{~N}_{2}, \bar{p}_{\mathrm{C}}=20$ bar, P8C7; (h) $1.71 \% \mathrm{C}_{2} \mathrm{H}_{6}, 0.19 \% \mathrm{C}_{2} \mathrm{H}_{4}, 13.10 \% \mathrm{O}_{2}(\varphi=0.5)$, $75 \% \mathrm{~N}_{2}, 10 \%$ Ar, $\bar{p}_{\mathrm{C}}=40$ bar, P8C8; (i) $2.02 \% \mathrm{C}_{2} \mathrm{H}_{6}, 0.22 \% \mathrm{C}_{2} \mathrm{H}_{4}, 7.75 \% \mathrm{O}_{2}(\varphi=1.0), 75 \% \mathrm{~N}_{2}, 15 \% \mathrm{Ar}$, $\bar{p}_{\mathrm{C}}=1$ bar, P8C9. (solid-line: NUIGMech1.0, dash-line: derived correlations (section 4.3))

\subsection{Individual effect of the studied parameters on IDT}

The general performance of NUIGMech1.0 and its fidelity in predicting the IDTs of the various $\mathrm{C}_{1}-\mathrm{C}_{2}$ binary fuel mixtures over the wide range of conditions studied has been demonstrated. In this section, the effects on IDTs of the studied parameters on the mixtures are discussed in detail, whereas the focus will be on the description of the individual parameters. To investigate the effect of each individual parameter on IDT, the $\mathrm{P} 5 \mathrm{C} 1$ and $\mathrm{P} 8 \mathrm{C} 1\left(\varphi=0.5, p_{\mathrm{C}}=1\right.$ bar, dilution $\left.=75 \%\right)$ conditions are chosen as the base cases for each binary-fuel combination (methane/ethylene and ethane/ethylene). For example, in studying the effect of equivalence ratio on ethylene IDT, we only perturb the equivalence ratio to 1.0 and 2.0 in the $\mathrm{P} 5 / 8 \mathrm{C} 1$ cases, so that the other parameters remain unchanged. Namely, by perturbing the equivalence ratio 
from 1.0 to 2.0 , the new cases are defined as $\left(\varphi=1.0, p_{\mathrm{C}}=1\right.$ bar, dilution $\left.=75 \%\right)$ and $\left(\varphi=2.0, p_{\mathrm{C}}=1 \mathrm{bar}\right.$, dilution $=75 \%$ ), respectively. The same procedure is followed for the other parameters. Therefore, the effect of each parameter on IDT in the temperature range $(800-2100 \mathrm{~K})$ is calculated as follows:

$$
\text { IDT ratio }=\frac{\left.\mathrm{IDT}\right|_{\varphi, p_{C}, \text { dilution,P } x C y}}{\left.\operatorname{IDT}\right|_{P x C 1}}
$$

Where " $x$ ", and " $y$ " are " 5,8 " and "2-9", respectively. In the above equation, values larger than unity indicate a decrease in reactivity, while values smaller than unity show an increase in reactivity in comparison to the base cases. The individual effect of each parameter on methane/ethylene and ethane/ethylene IDTs are presented in Figure 5. For better visualization, the y-axis in Figure 5 is scaled in " $\log _{2}$ " so that $2^{-1}, 2^{0}$, and $2^{1}$ refers to a factor of two decrease, no change, and a factor of two increase in IDT ratio, respectively. It is seen that the individual effect of each parameter on IDT changes qualitatively and quantitatively over the temperature range studied. In this regard, the individual effect of the studied parameters such as the binary blend composition, pressure, equivalence ratio, and dilution on IDT predictions of methane/ethylene and ethane/ethylene mixtures are discussed in detail.

\subsubsection{Effect of binary blend compositions}

As seen in Figure 5(a), decreasing the ethylene concentration in the methane and the ethane blends have a significant semi-Gaussian distribution on decreasing reactivity, especially in the intermediate temperature regime ( $1200 \mathrm{~K})$. Specifically, decreasing the ethylene concentration in the methane/ethylene blend progressively from $50 \%$ to $30 \%$ and finally to $10 \%$ suppresses the average mixture reactivity by approximately $120 \%$ and $990 \%$, respectively, while decreasing the ethylene concentration in the ethane/ethylene blend only suppresses the reactivity by approximately $11 \%$ and $22 \%$, respectively. This clearly shows that methane is much more sensitive to ethylene blending than ethane. Moreover, Figure 5(a) shows that, although the reduction in ethylene concentration has a less negative effect on the reactivity of the methane/ethylene mixtures at high $(\geq 1670 \mathrm{~K})$ and low temperatures ( $\leq 900 \mathrm{~K})$, the effect of ethylene concentration on the reactivity of the ethane/ethylene mixture is minor over the entire temperature range. In this way, one can see in Figure 5(a) that decreasing ethylene concentration has no significant effect on the reactivity of ethane/ethylene mixtures at temperatures higher than $1670 \mathrm{~K}(1000 / T=0.6)$. To understand this more fully, sensitivity analyses to IDT, including both brute-force and direct sensitivity analyses $^{27}$ (Figure 6) followed by flux analyses (not shown here for brevity) were conducted at $1200 \mathrm{~K}$ (0.833) where the effect of ethylene addition is most prominent. In the brute-force and the direct sensitivity analyses, the sensitivity coefficient $(\mathrm{S})$ is calculated as:

$$
S=\frac{\ln \left(\frac{\tau^{+}}{\tau^{-}}\right)}{\ln \left(\frac{2}{0.5}\right)}
$$

As shown above, the rate constant for each reaction is increased/decreased by a factor of two, and IDTs are calculated as $\tau^{+}$(increased) and $\tau^{-}$(decreased), respectively. A positive sensitivity coefficient indicates inhibition of reactivity, while a negative coefficient indicates a promotion in reactivity. Figure 6 indicates 
that adding ethylene to methane makes the chemistry more complex in terms of the number of important reactions involved (sensitivity coefficient $\geq 0.1$ ) in IDT in comparison to addition to ethane.

Figure 6 shows that increasing methane concentration in the methane/ethylene blend promotes the chain-termination reactions: $\dot{\mathrm{C}} \mathrm{H}_{3}+\dot{\mathrm{C}} \mathrm{H}_{3}(+\mathrm{M}) \leftrightarrow \mathrm{C}_{2} \mathrm{H}_{6}(+\mathrm{M})$ and $\dot{\mathrm{C}}_{3}+\mathrm{HO}_{2} \leftrightarrow \mathrm{CH}_{4}+\mathrm{O}_{2}$. Simultaneously, increasing the methane concentration promotes the reactions: $\mathrm{CH}_{4}+\dot{\mathrm{O}} \mathrm{H} \leftrightarrow \dot{\mathrm{C}} \mathrm{H}_{3}+\mathrm{H}_{2} \mathrm{O}, \mathrm{CH}_{4}+\ddot{\mathrm{O}} \leftrightarrow \dot{\mathrm{C}} \mathrm{H}_{3}$ $+\dot{\mathrm{O}} \mathrm{H}, \dot{\mathrm{C}} \mathrm{H}_{3}+\mathrm{HO}_{2} \leftrightarrow \mathrm{CH}_{3} \dot{\mathrm{O}}+\dot{\mathrm{O}} \mathrm{H}, \dot{\mathrm{C}} \mathrm{H}_{3}+\mathrm{O}_{2} \leftrightarrow \mathrm{CH}_{2} \mathrm{O}+\dot{\mathrm{O}} \mathrm{H}$ in competition with the reactions: $\mathrm{C}_{2} \mathrm{H}_{4}+$ $\dot{\mathrm{OH}} \leftrightarrow \dot{\mathrm{C}}_{2} \mathrm{H}_{3}+\mathrm{H}_{2} \mathrm{O}, \mathrm{C}_{2} \mathrm{H}_{4}+\ddot{\mathrm{O}} \leftrightarrow \dot{\mathrm{C}}_{2} \mathrm{CHO}+\dot{\mathrm{H}}, \dot{\mathrm{C}}_{2} \mathrm{H}_{3}+\mathrm{O}_{2} \leftrightarrow \dot{\mathrm{C}} \mathrm{H}_{2} \mathrm{CHO}+\ddot{\mathrm{O}}$, which all dramatically suppress the blends reactivity at $1200 \mathrm{~K}$. Thus, increasing ethylene concentration in the fuel blend promotes reactivity by inhibiting methyl radical $\left(\dot{\mathrm{C}}_{3}\right)$ reactions but instead promotes reactions of vinyl radicals, which are more reactive than methyl radicals. As seen in Figure 6, increasing the ethane concentration $(50 \% \rightarrow 90 \%)$ in the ethane/ethylene blend at $1200 \mathrm{~K}$ has no significant effect on the ten most prominent reactions, so that this increment promotes $\dot{\mathrm{H}}+\mathrm{O}_{2}(+\mathrm{M}) \leftrightarrow \mathrm{HO}_{2}(+\mathrm{M}), \dot{\mathrm{H}}+\mathrm{HO}_{2} \leftrightarrow \dot{\mathrm{O}} \mathrm{H}+\dot{\mathrm{OH}}$, and $\dot{\mathrm{C}}_{3}+$ $\mathrm{HO}_{2} \leftrightarrow \mathrm{CH}_{3} \mathrm{O}+\dot{\mathrm{OH}}$ against the suppression of the important reaction: $\dot{\mathrm{C}}_{2} \mathrm{H}_{3}+\mathrm{O}_{2} \leftrightarrow \dot{\mathrm{C}} \mathrm{H}_{2} \mathrm{CHO}+\ddot{\mathrm{O}}$. Thus, the decrease in reactivity of the ethane/ethylene fuel blend with increasing ethane concentration (Figure 5(a)), mainly stems from competition among the chain propagating reactions: $\dot{\mathrm{C}}_{2} \mathrm{H}_{5}+\mathrm{O}_{2} \leftrightarrow \mathrm{C}_{2} \mathrm{H}_{4}+\mathrm{HO}_{2}$ and $\mathrm{C}_{2} \mathrm{H}_{4}+\dot{\mathrm{H}}(+\mathrm{M}) \leftrightarrow \dot{\mathrm{C}}_{2} \mathrm{H}_{5}(+\mathrm{M})$ and the chain branching reaction: $\dot{\mathrm{C}}_{2} \mathrm{H}_{3}+\mathrm{O}_{2} \leftrightarrow \dot{\mathrm{C}}_{2} \mathrm{CHO}+\ddot{\mathrm{O}}$ by scavenging $\dot{\mathrm{C}}_{2} \mathrm{H}_{5}$ radical and $\mathrm{O}_{2}$ molecules from the radical pool. 

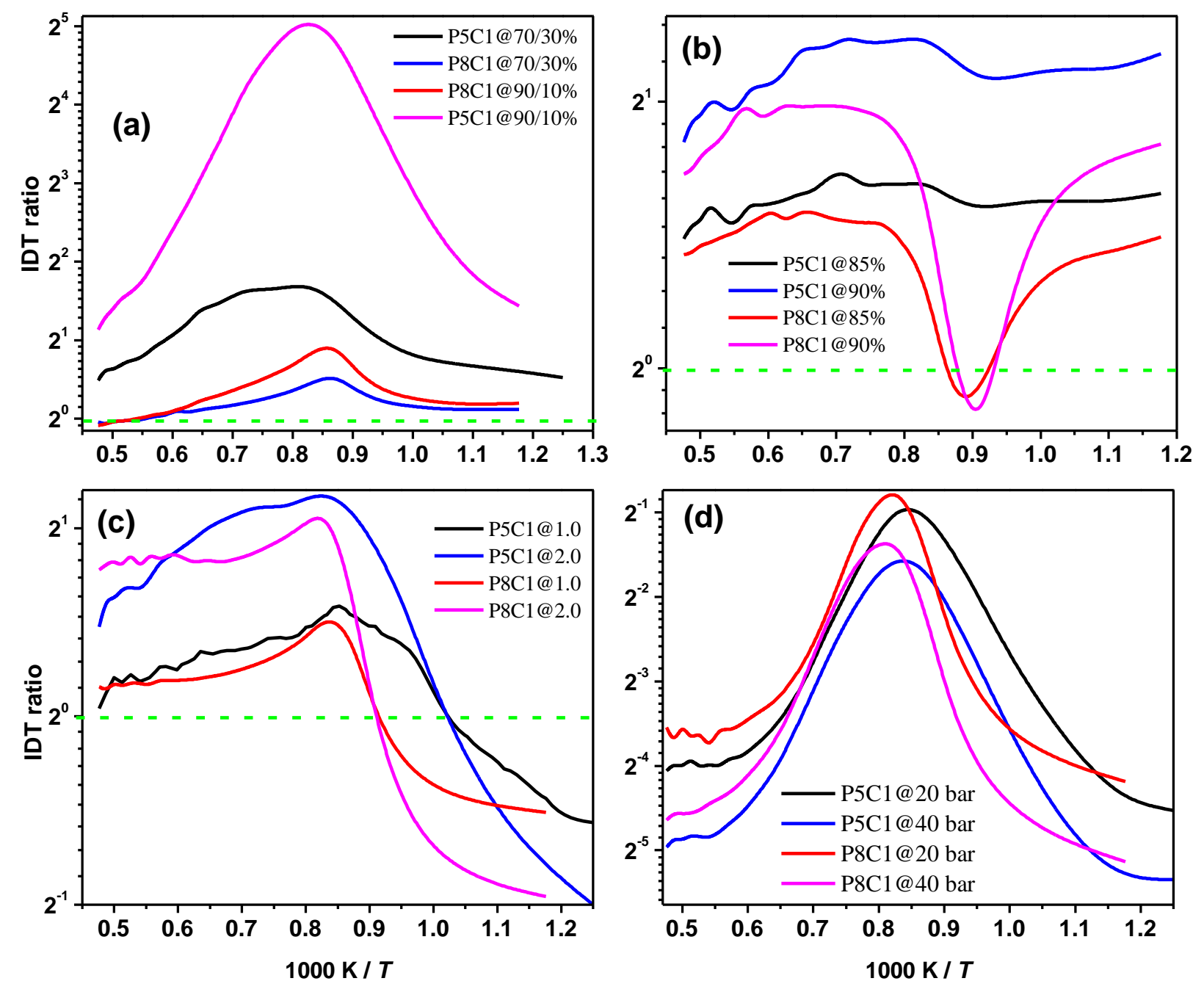

Figure 5. Individual effects of the studied parameters on methane/ethylene and ethane/ethylene IDTs: (a) effect of blending composition; (b) effect of dilution level; (c) effect of equivalence ratio; and (d) effect of pressure. 


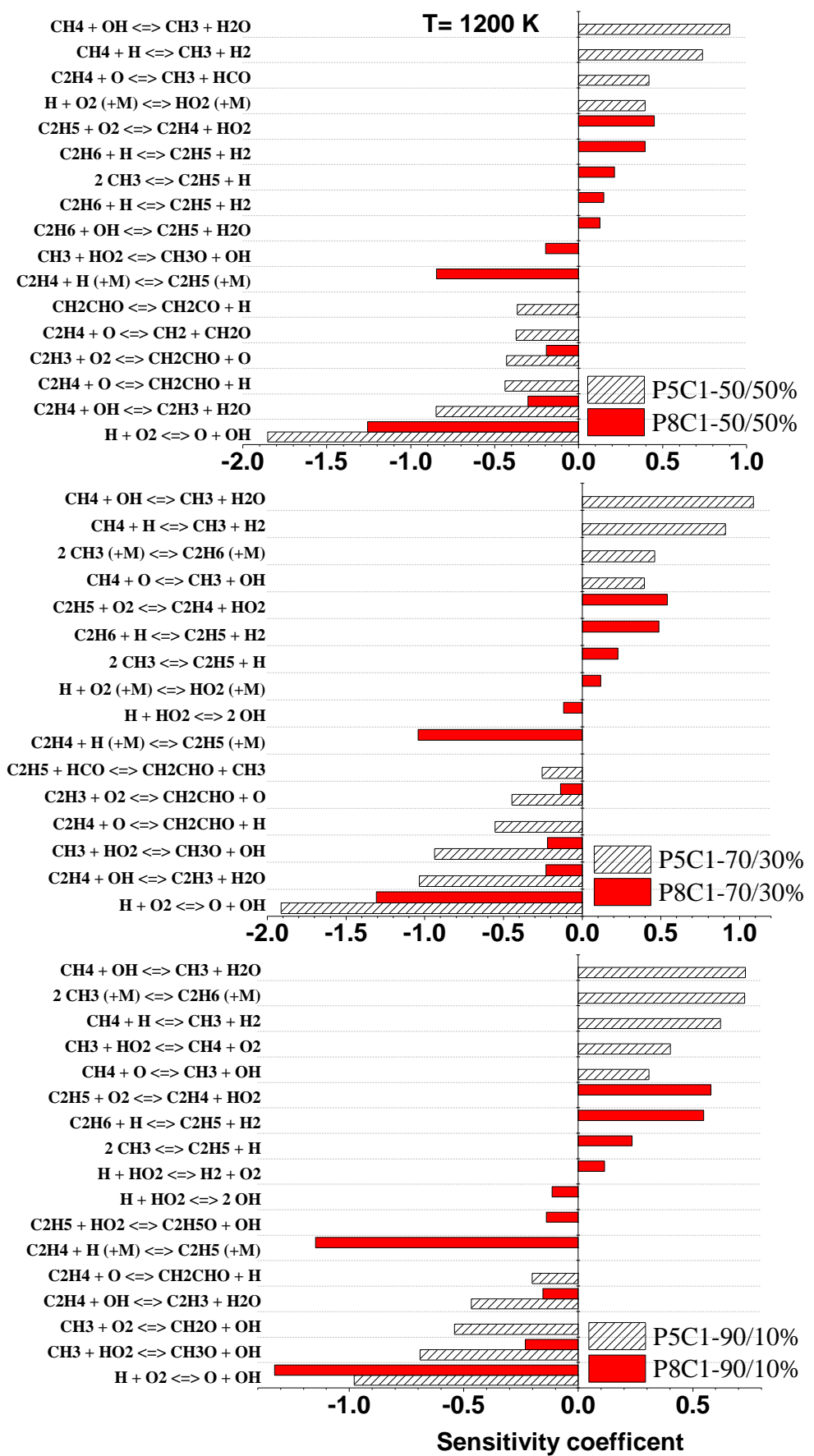

Figure 6. Sensitivity analysis of IDT corresponding to the temperature of $1200 \mathrm{~K}(0.833)$ in Figure 5(a).

\subsubsection{Effect of dilution}

The effect on the reactivity of increasing dilution on the methane/ethylene and ethane/ethylene mixtures is demonstrated in Figure 5(b). It is seen that increasing dilution from $75 \%$ to $85 \%$ and then $90 \%$ in the methane/ethylene mixtures decreases reactivity by approximately 55\% and $115 \%$, respectively. However, this effect on the ethane/ethylene mixture is not monotonic. Surprisingly, it is seen in Figure 5(b) that increasing the dilution level in the ethane/ethylene mixture, not only suppresses the negative effect of dilution on reactivity within the temperature range of 1000-1250 K but enhances reactivity by $\sim 10 \%$ at $1100 \mathrm{~K}(0.909)$. In this regard, three new experimental datasets within the target temperature 
range (1000-1200 K), under 1 bar, $50 \% \mathrm{C}_{2} \mathrm{H}_{6}+50 \% \mathrm{C}_{2} \mathrm{H}_{4}, \varphi=0.5$, and dilution levels (Ar) of 75\%, 85\%, and $90 \%$ conditions were performed. However, some of the measured IDTs (> 4-5 ms) are located at the upper working limit of NUIG-LPST. As mentioned, although some of the IDTs are relatively long for available LPST in $\mathrm{C}^{3}$-NUIG, most of them have been taken under tailoring conditions with almost plateau pressure profiles behind the reflected shock $(d p / d t \sim 0)$ during the induction time before ignition. However, those data with significant $\mathrm{dp} / \mathrm{dt}$ behind the reflected shock had already been removed from the graph for increasing the data reliability demonstrated in Figure 7. As seen in Figure 7, although NUIGMech1.0 could somehow capture the behaviour and the IDT trends by increasing the dilution level from $75 \%$ to $90 \%$, it fails to reproduce the experimental IDTs beyond the dilution level of $75 \%$ so that the predictions of NUIGMech1.0 are consistently shorter than the experimental measurements over the temperature range studied. By comparing the effect of dilution on the reactivities of the methane/ethylene and ethane/ethylene blends shown in Figure 8, it is inferred that this behaviour stems from the effect of dilution (third body) and the competition between $\dot{\mathrm{C}}_{2} \mathrm{H}_{4}+\dot{\mathrm{H}}(+\mathrm{M}) \leftrightarrow \dot{\mathrm{C}}_{2} \mathrm{H}_{5}(+\mathrm{M})$ and $\dot{\mathrm{C}}_{2} \mathrm{H}_{5}+\mathrm{O}_{2} \leftrightarrow \mathrm{C}_{2} \mathrm{H}_{4}+\mathrm{H}_{2}$ in consuming $\dot{\mathrm{C}}_{2} \mathrm{H}_{5}$ radicals. On the one hand, increasing the dilution level intensifies the reverse reaction of $\dot{\mathrm{C}}_{2} \mathrm{H}_{4}+\dot{\mathrm{H}}$ $(+\mathrm{M}) \leftrightarrow \dot{\mathrm{C}}_{2} \mathrm{H}_{5}(+\mathrm{M})$ which produces more reactive $\dot{\mathrm{H}}$ atoms. On the other hand, increasing the dilution level decreases the oxygen concentration in the radical pool, which suppresses the reaction $\dot{\mathrm{C}}_{2} \mathrm{H}_{5}+\mathrm{O}_{2} \leftrightarrow$ $\mathrm{C}_{2} \mathrm{H}_{4}+\mathrm{HO}_{2}$. Also, Figure 8 shows that increasing the dilution level inhibits the reaction of $\mathrm{H}_{2} \mathrm{O}_{2}(+\mathrm{M}) \leftrightarrow$ $\dot{\mathrm{O}} \mathrm{H}+\dot{\mathrm{O}} \mathrm{H}(+\mathrm{M})$ and simultaneously promotes $\dot{\mathrm{C}} \mathrm{H}_{3}+\mathrm{H}_{2} \leftrightarrow \mathrm{CH}_{3} \dot{\mathrm{O}}+\dot{\mathrm{O}} \mathrm{H}, \dot{\mathrm{H}}+\mathrm{O}_{2}(+\mathrm{M}) \leftrightarrow \mathrm{HO}_{2}(+\mathrm{M})$, and $\dot{\mathrm{H}}+\mathrm{H}_{2} \leftrightarrow \dot{\mathrm{O} H}+\dot{\mathrm{O}} \mathrm{H}$. Apart from the intermediate temperature regime, it is seen in Figure 5(b) that the effect on the reactivity of increasing the dilution level is much less pronounced in the ethane/ethylene mixtures compared to the methane/ethylene mixtures.

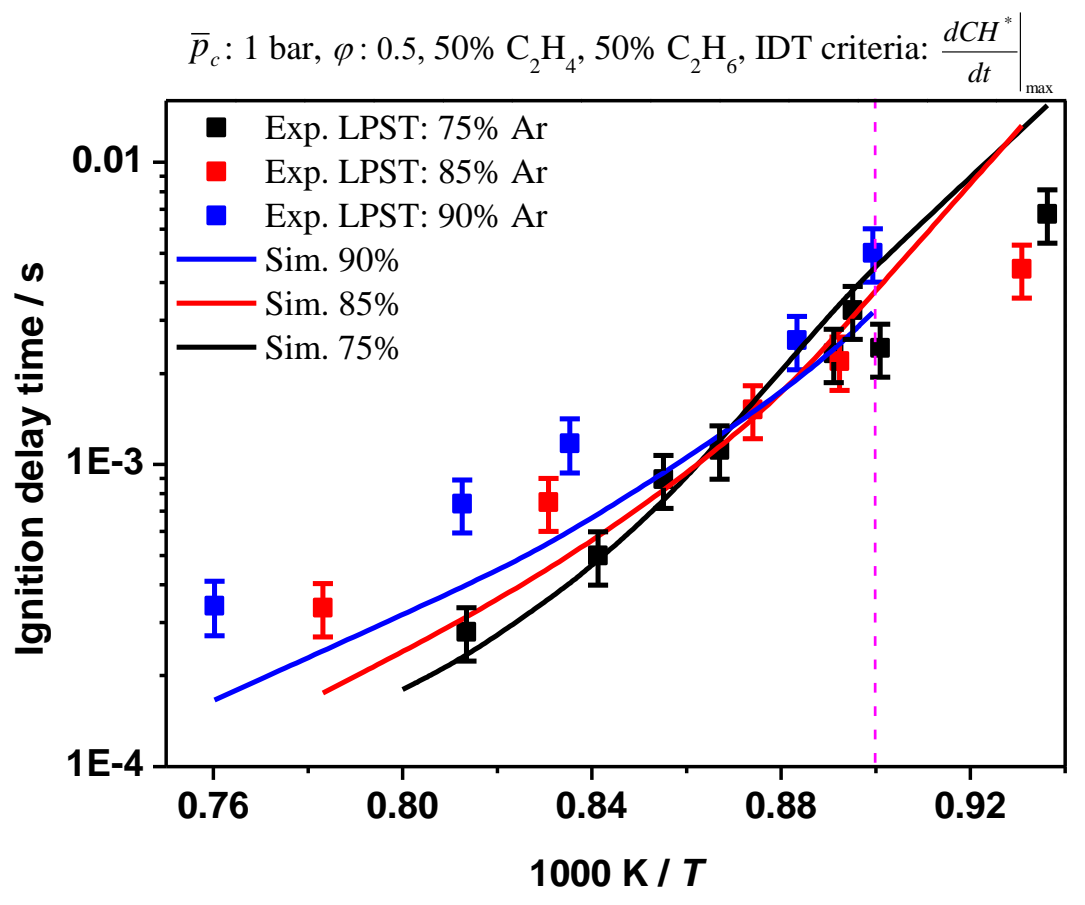

Figure 7. Experimental and simulation data for ethane/ethylene oxidation concerning Figure 5(b). The magenta dash-line refers to the turning point temperature (0.909) in Figure 5(b). 


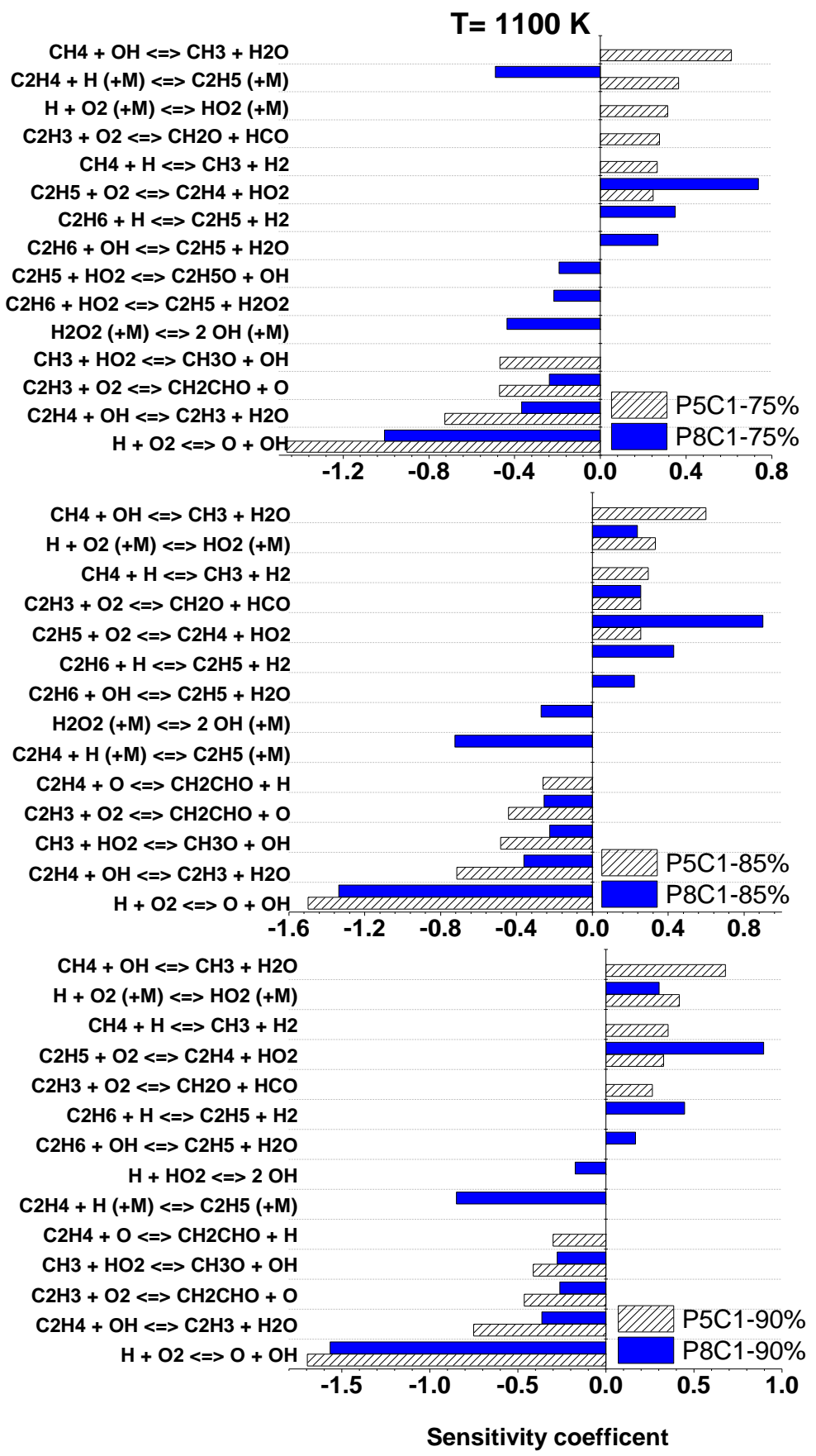

Figure 8. Sensitivity analysis of IDT corresponding to the temperature $1100 \mathrm{~K}(0.91)$ in Figure 5(b).

\subsubsection{Effect of equivalence ratio}

The effect of increasing equivalence ratio from 0.5 to 1.0 and 2.0 on the reactivity of the methane/ethylene and ethane/ethylene mixtures is depicted in Figure 5(c). Increasing the equivalence ratio has a complex effect on the reactivity of the mixtures over the temperatures studied. Increasing the equivalence ratio has a drastic effect on decreasing the mixtures' reactivity in the temperature range 800 $1200 \mathrm{~K}$, which is followed by a mild effect in increasing mixture reactivity at temperatures $\geq 1200 \mathrm{~K}$. It is seen in Figure 5(c) that, although the reactivity of ethane/ethylene blends is less sensitive to an increasing equivalence ratio with temperature compared to methane/ethylene mixtures, it shows a higher sensitivity in the temperature range 1050-1200 K. The maximum gradient in decreasing the reactivity of the 
ethane/ethylene mixtures $\left(\left.\frac{\partial I D T \text { ratio }}{\partial T}\right|_{\text {max }}\right)$ is about 0.73 and $1.36 \% / \mathrm{K}$ (at $1100 \mathrm{~K}$ ) at equivalence ratios of 1.0 and 2.0 respectively, in the temperature range $800-1200 \mathrm{~K}$, while the values for the methane/ethylene mixtures are about 0.4 and $0.82 \% \mathrm{~K}^{-1}$ (at $1000 \mathrm{~K}$ ) at equivalence ratios of 1.0 and 2.0, respectively. The reactivity of the fuel-rich mixtures is much more affected by changes in temperature, especially in the 800 $1200 \mathrm{~K}$ temperature range. In this regard, Figures 9 and S40 show that increasing the equivalence ratio in the methane/ethylene blends at $1200 \mathrm{~K}$ intensifies $\mathrm{H}$-atom abstraction from $\mathrm{CH}_{4}$ and $\mathrm{C}_{2} \mathrm{H}_{4}$ by $\mathrm{H}$ atoms instead of $\dot{\mathrm{OH}}$ radicals. This effect makes the system less reactive (Figure S41). However, increasing the equivalence ratio promotes the chain branching reaction of $\dot{\mathrm{C}}_{2} \mathrm{H}_{3}+\mathrm{O}_{2} \leftrightarrow \dot{\mathrm{C}}_{2} \mathrm{CHO}+\ddot{\mathrm{O}}$ compared to the more reactive chain branching reaction $\mathrm{C}_{2} \mathrm{H}_{4}+\ddot{\mathrm{O}} \leftrightarrow \dot{\mathrm{C}} \mathrm{H}_{2} \mathrm{CHO}+\dot{\mathrm{H}}$, so that as seen in Figure S41 this promotion reduces the blend reactivity. Also, Figure 9 shows that increasing the equivalence ratio to 2.0 promotes the reverse reaction of $\mathrm{C}_{3} \mathrm{H}_{6}+\dot{\mathrm{H}} \leftrightarrow \mathrm{C}_{2} \mathrm{H}_{4}+\dot{\mathrm{C}} \mathrm{H}_{3}$ in competition with $\mathrm{C}_{2} \mathrm{H}_{4}+\ddot{\mathrm{O}} \leftrightarrow \ddot{\mathrm{C}} \mathrm{H}+\mathrm{CH}_{2} \mathrm{O}$ and $\dot{\mathrm{C}} \mathrm{H}_{2} \mathrm{CHO} \leftrightarrow \mathrm{CH}_{2} \mathrm{CO}+\dot{\mathrm{H}}$.

Similar to the methane/ethylene blend, it is shown in Figures 9 and S42 that increasing the equivalence ratio of the ethane/ethylene blend from 0.5 to 2.0 at $1200 \mathrm{~K}$ changes the $\mathrm{H}$-atom abstraction pattern from $\dot{\mathrm{O}} \mathrm{H}$ radicals to $\dot{\mathrm{H}}$ atoms so that this shift makes the blend less reactive at $1200 \mathrm{~K}$. In fact, decreasing oxygen concentration by increasing equivalence ratio and also competition between $\mathrm{C}_{2} \mathrm{H}_{6}$ and $\mathrm{C}_{2} \mathrm{H}_{4}$ in consuming $\dot{\mathrm{H}}$ atoms and $\dot{\mathrm{OH}}$ radicals and producing $\dot{\mathrm{C}}_{2} \mathrm{H}_{5}$ and $\dot{\mathrm{C}}_{2} \mathrm{H}_{4}$ radicals affect blend reactivity due to the higher reactivity of vinyl radicals compared to ethyl radicals in the blends studied. 


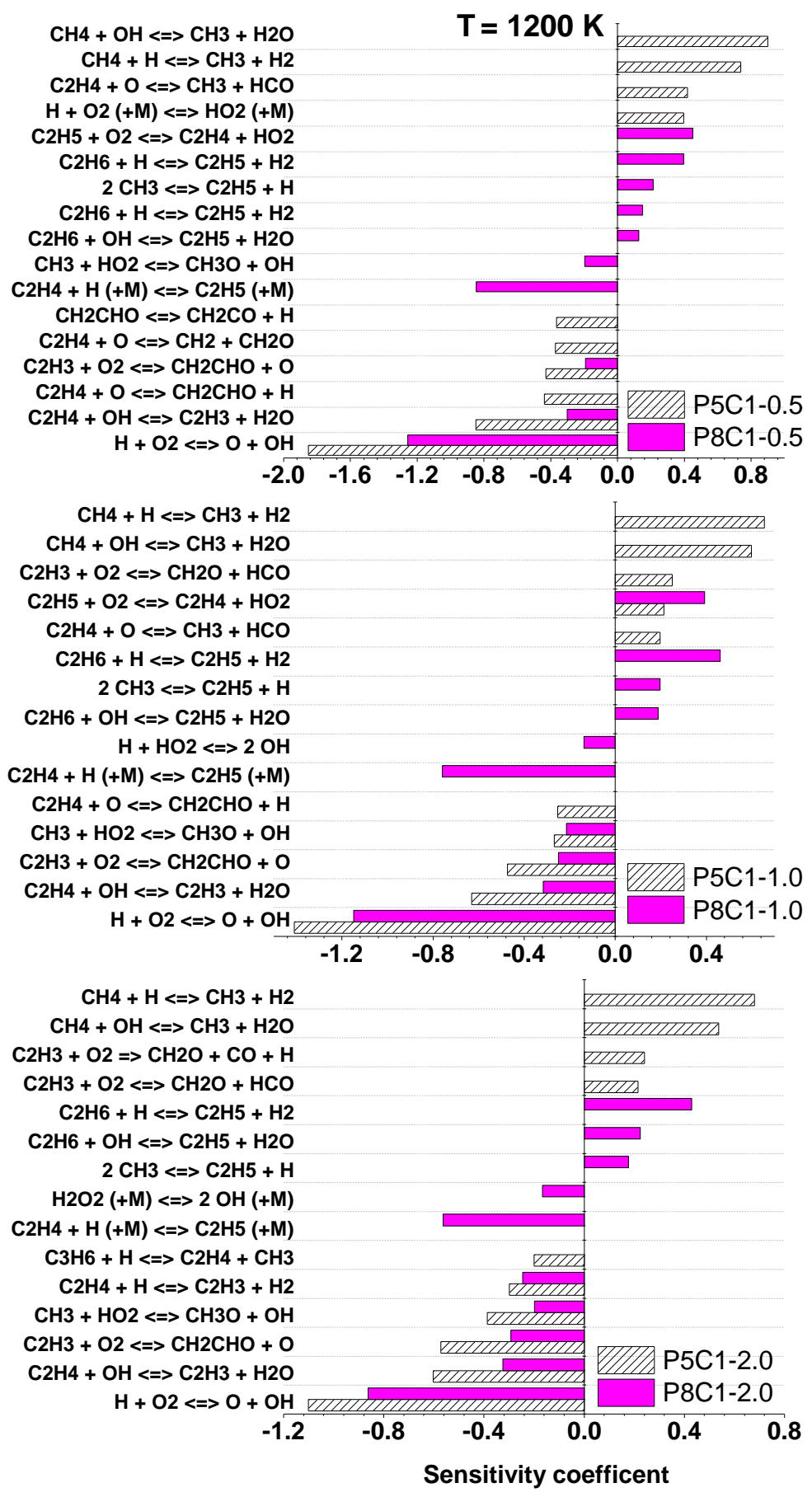

Figure 9. Sensitivity analysis of IDT corresponding to the temperature $1200 \mathrm{~K}(0.833)$ in Figure 5(c).

\subsubsection{Effect of pressure}

The effect of pressure on the reactivity of the methane/ethylene and ethane/ethylene blends is demonstrated in Figure 5(d). One can see that increasing pressure increases the reactivity of all mixtures. In this regard, it can be seen in Figure 5(d) that increasing the pressure from 1 to 40 bar has a Gaussian distribution effect on reactivity with temperature, in that it decreases reactivity in the temperature range $1050-1550 \mathrm{~K}$, while its effect on the reactivity is almost constant at $T \geq 1540 \mathrm{~K}$ and $T \leq 1050 \mathrm{~K}$ for the ethane/ethylene blends and at $T \leq 920 \mathrm{~K}$ for the methane/ethylene blends. Moreover, Figure 5(d) shows that although the positive effect of increasing pressure for the methane/ethylene blends at $T \geq 1200 \mathrm{~K}$ is 
higher than for the ethane/ethylene mixtures, this trend is reversed at $T \leq 1200 \mathrm{~K}$. At $1200 \mathrm{~K}$, the minimum effect of the Gaussian distribution on increasing the reactivity of the methane/ethylene mixtures is about $48 \%$ at 20 bar and $66 \%$ at 40 bar, while the values for the ethane/ethylene mixtures at 20 and 40 bar are $42 \%$ and $62 \%$, respectively. In addition, Figure 5(d) shows that although the effect of pressure on the reactivity of the methane/ethylene mixtures is more sensitive to temperature in comparison to the ethane/ethylene mixtures, this effect shows a very high sensitivity to temperature for the ethane/ethylene mixtures in the temperature range 1050-1500 K. Increasing the temperature of the ethane/ethylene mixture from $1050 \mathrm{~K}$ to $1220 \mathrm{~K}$ decreases the reactivity by approximately $48 \%$, while further increasing the temperature to $1500 \mathrm{~K}$ retrieves the mixture's reactivity. Furthermore, it is demonstrated in Figure 5(d) that the reactivity of ethane/ethylene mixtures is more sensitive to pressure rise compared to the methane/ethylene mixtures. However, they show almost the same sensitivity and dependency at hightemperatures $(\geq 1666 \mathrm{~K})$ and low-temperatures $(\leq 900 \mathrm{~K})$. Figure 5(d) also shows that for both the methane/ethylene and ethane/ethylene mixtures, increasing pressure has the most prominent effect on reactivity in the temperature range $1100-1330 \mathrm{~K}$.

Sensitivity and flux analyses (Figures 10, S43 and S44) reveal that increasing the pressure of the methane/ethylene and the ethane/ethylene blends from 1 to 40 bar at $1200 \mathrm{~K}$, intensifies $\mathrm{H}$-atom abstraction from $\mathrm{CH}_{4}, \mathrm{C}_{2} \mathrm{H}_{6}$, and $\mathrm{C}_{2} \mathrm{H}_{4}$ by $\dot{\mathrm{O}} \mathrm{H}$ and $\mathrm{HO}_{2}$ radicals and simultaneously inhibits abstraction by $\dot{\mathrm{H}}$ atoms. These may stem from the promotions in importance of the reactions: $\dot{\mathrm{H}}+\mathrm{O}_{2}(+\mathrm{M}) \leftrightarrow \mathrm{H}_{2}(+\mathrm{M})$ and $\mathrm{H}_{2} \mathrm{O}_{2}$ $(+\mathrm{M}) \leftrightarrow \dot{\mathrm{O}} \mathrm{H}+\dot{\mathrm{O}} \mathrm{H}(+\mathrm{M})$ with increasing pressure. One can see in Figures 10 and S44 that these effects are more pronounced in the ethane/ethylene blend, and thus the blend shows a higher sensitivity to the effects at $1200 \mathrm{~K}$. As seen in Figure 10, increasing the pressure at $1200 \mathrm{~K}$ suppresses the $\mathrm{C}_{2} \mathrm{H}_{4}+\ddot{\mathrm{O}} \leftrightarrow \ddot{\mathrm{C}} \mathrm{H}+$ $\mathrm{CH}_{2} \mathrm{O} / \dot{\mathrm{C}} \mathrm{H}_{3}+\mathrm{HC} \mathrm{O}$ reactions, and in particular the important chain branching reaction $\mathrm{C}_{2} \mathrm{H}_{4}+\mathrm{O} \leftrightarrow$ $\dot{\mathrm{C}} \mathrm{H}_{2} \mathrm{CHO}+\dot{\mathrm{H}}$. Moreover, Figures 10 and S44 demonstrate that increasing the pressure of the ethane/ethylene blend at $1200 \mathrm{~K}$ suppresses the reverse chain branching reaction $\dot{\mathrm{C}}_{2} \mathrm{H}_{4}+\dot{\mathrm{H}}(+\mathrm{M}) \leftrightarrow \dot{\mathrm{C}}_{2} \mathrm{H}_{5}$ $(+\mathrm{M})$ and simultaneously promotes the chain propagating reactions $\mathrm{C}_{2} \mathrm{H}_{6}+\mathrm{HO}_{2} \leftrightarrow \dot{\mathrm{C}}_{2} \mathrm{H}_{5}+\mathrm{H}_{2} \mathrm{O}_{2}$ and $\mathrm{C}_{2} \mathrm{H}_{4}$ $+\mathrm{HO}_{2} \leftrightarrow \dot{\mathrm{C}}_{2} \mathrm{H}_{3}+\mathrm{H}_{2} \mathrm{O}_{2}$. All of these effects make the methane/ethylene, and the ethane/ethylene blends less reactive compared to the base cases (P5C1 and P8C1). 


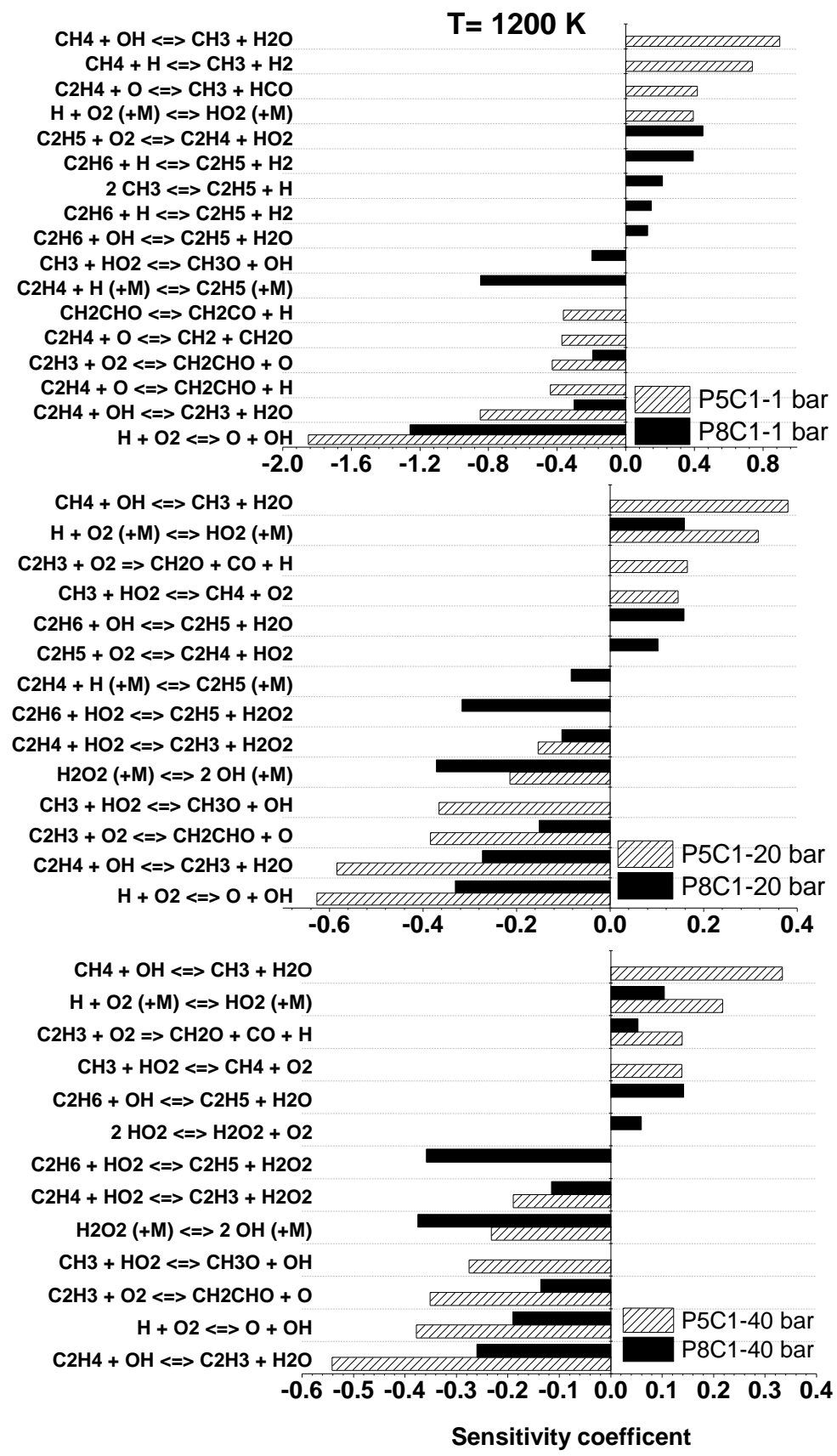

Figure 10. Sensitivity analysis of IDT corresponding to the temperature $1200 \mathrm{~K}(0.833)$ in Figure 5(d).

\subsection{Correlations and their performances}

Having reliable global expressions that can properly explain the reactivity of different mixtures under different physio-chemical conditions is demanding. Global correlations can significantly decrease the computational time of real-time/scale combustion systems and CFD simulations. Hence, in this section, several correlations are derived based on the constant volume simulations of NUIGMech1. $0^{13}$, which we have shown can reasonably predict IDTs for methane/ethylene, methane/ethane, and ethane/ethylene mixtures over a wide range of binary blended fuel conditions. The applied procedure for deriving the correlations has already been discussed by the authors ${ }^{13}$. The validity ranges of the correlations are: $1 \leq p$ $\leq 50 \mathrm{~atm}, 800 \leq T \leq 2000 \mathrm{~K}, 0.25 \leq \varphi \leq 3.0,75 \% \leq$ dilution $\leq 95 \%$, and Fuel_1/Fuel_2: 30/70\%, 50/50\%, 
and 70/30\% which stems from the targets of the current study. Thus, the following simple correlation style is used to mathematically explain the relationship for the conditions studied:

$$
\tau_{\text {idt }, \text { corr }}=10^{\mathrm{A}} \exp \left(\frac{\mathrm{B}}{T}\right)[\text { Fuel_1 }]^{\mathrm{C}}[\text { Fuel_2 }]^{\mathrm{D}}[\text { Oxygen }]^{\mathrm{E}}[\text { Diluent }]^{\mathrm{F}}
$$

where the concentrations $\left(\mathrm{mol} \mathrm{m}^{-3}\right)$ of fuels, oxygen, and diluent are calculated based on the ideal gas law in accordance with the partial pressure of each species in the mixture at a specific temperature. Tables 3-5 show that the correlations are evaluated by sub-dividing the numerically studied conditions into two regimes; a) low, intermediate, and high temperatures; and b) high- and low-pressure, corresponding to the different chemistry controlling ignition over these conditions. However, based on our correlation procedure (constant-volume adiabatic simulations), the derived correlations for the low-temperature regime are not able to capture the experimental IDTs where non-ideal effects (mostly heat loss effects) are prominent. Therefore, the performance of the correlations is evaluated only in the intermediate-to-high temperature regime. In this regard, Origin 8.5 software ${ }^{28}$ is used to derive the correlation parameters included in Eq. (3). The coefficients of the extracted correlations for methane/ethylene, methane/ethane, and ethane/ethylene, including standard errors and validity ranges over the studied conditions, are presented in Tables 3-5.

The performance of the derived correlations versus the available experimental IDT data in the literature (methane/ethane) and the newly-taken data of the present study (methane/ethylene and ethane/ethylene) was already shown in Figures 2-4. In these figures, the red dashed lines refer to the derived correlations. However, the red dashed line is replaced by a blue line if one parameter (e.g., pressure or dilution) is outside the range of correlation. It is seen in Figure 2 that the correlation formula can duplicate the experimental IDT data trend of the methane/ethylene mixtures over a wide range of conditions. The correlation coefficients for the methane/ethylene mixtures are presented in Table 3. Although, as seen in Figures 2(a), (e), and (i), correlating the simulation results using the format presented in Eq. (3) is inaccurate with significant uncertainties due to the highly non-linear behavior of the methane/ethylene mixtures at pressures in the range 1-15 atm. As already shown in the sensitivity analysis plots, the highly non-linearity of IDTs within 1-15 bar range almost stems from high sensitivity of the IDTs to $\dot{\mathrm{H}}+\mathrm{O}_{2}(+\mathrm{M})$ $\leftrightarrow \mathrm{HO}_{2}(+\mathrm{M})$ and $\dot{\mathrm{H}}+\mathrm{O}_{2} \leftrightarrow \ddot{\mathrm{O}}+\dot{\mathrm{O}} \mathrm{H}$ which change significantly with pressure over the range investigated. In this regard, the average $\left(\bar{\delta}_{\text {corr-exp }}\right)$ and standard $\left(\bar{\sigma}_{\text {corr-exp }}\right)$ deviation of the methane/ethylene correlations from the experimental data (only shock-tube data) over the studied temperature range is presented in Table 6 .

Here, it should be noted that highly non-linear behavior of the oxidation chemistry of the studied binary blended fuels over certain ranges of the studied conditions may cause that the simple form of the correlation presented in Eq. (3) fails to accurately predict experimental IDTs, especially in the range 1-20 atm. In fact, high sensitivity of IDT to some non-linear dependency of vital reactions and also changing the vital reactions over certain ranges of fuel concentration, temperature, and pressure make the chemically predicted IDTs more scattered in terms of the defined parameters in Eq. (3), so that the derived regressions would be less accurate depending on the scattering level of the calculated IDTs by the parent high fidelity 
chemical mechanism. Such deviations could be somehow understood by looking at $\mathrm{R}^{2}, \chi^{2}$, and importantly high standard errors of the derived coefficients for the parameters in Eq. (3). Therefore, as seen in the relevant table for methane + ethylene blends, it was not possible to derive a proper simple shape correlation for IDTs in the pressure range of 1-15 atm. For compensating the issue, the authors tried to divide the correlation zones into several regions in accordance with temperature, pressure, and equivalence ratios and bundle the same pose regions into one category to get more accurate correlations. Moreover, as mentioned above, in some regions related to low temperatures in which the experimental IDTs measured using RCM, again, some discrepancies between the correlation and the model predictions could be seen. These discrepancies stem from the fact that the correlations are derived based on constant volume adiabatic calculations, while the experiments suffer from non-idealities such as heat loss, which substantially can affect the measured IDT. However, these non-idealities can be robustly treated in the RCM simulations of the parent chemical model by imposing a volume history profile. Thus, the red dashed lines for IDTs above 10 ms often show under prediction, which can be explained by the heat loss effect that occurs in the RCM experiments, which are not taken into account in the correlations. Furthermore, the IDT criterion is another parameter that may affect the performance of the correlations versus the parent chemical mechanism. The correlations have been derived based on IDTs calculated by the maximum gradient in pressure history, while some experimental IDTs and their respective simulation data (specially $<10$ bar) were determined using different definitions such as the maximum gradient in $\mathrm{CH}^{*}$ or $\mathrm{OH}^{*}$ history.

Figure 3 shows that the simple derived correlations which are reported in Table 4 for the methane/ethane mixtures can reasonably reproduce the experimental IDTs and their trends, even for those outside of the range of the correlation (Figures 3(a) and (i); dilution level > 95\%). Thus, the average and standard deviation of the methane/ethane correlations from the experimental data (only shock tube data) over the temperature range studied are provided in Table 7. It is seen that the average deviation between the correlations and the experimental data over the studied conditions in the high-temperature regime is approximately $35 \%$.

The performance of the derived correlations in predicting the IDTs of the ethane/ethylene mixtures is shown in Figure 4. The coefficients of the correlations are presented in Table 5 at both low and high temperatures. By comparing the experimental data and the correlations in Figure 4, it is apparent that the derived correlations can acceptably predict the measured IDTs with an accuracy comparable to NUIGMech1.0. In this regard, it is observed in Table 8 that the average deviation between the correlations and the experimental data over the studied conditions in the high-temperature regime is approximately $40 \%$.

Furthermore, by increasing the compressed pressure to 20 and 40 bar, it is seen in Figures 2-4 that all of the correlations can acceptably predict experimental IDTs even in the intermediate-to-low temperature regime. This stems from the fact that the high-pressure chemistry does not significantly change within the 15-50 bar (3.33 times) window in deriving the correlations, while this effect is dramatically sensitive to changes in pressure in the range 1-15 bar (15 times). This fact is somehow demonstrated in Figure 11. Although the correlations were derived over 1-50 atm, according to the pressure effect discussed above, 
the correlation could satisfactorily predict the experimental IDTs (within $\pm 40 \%$ ) over 125 bar, low temperature, and relatively short IDT regimes in where the heat loss effect would be minor in RCM facilities. This finding could be interesting in terms of mimicking gas engine operating pressure, which is almost above 40 bar. Furthermore, it is interesting to note that the performance of the simple correlations in reproducing the experimental IDTs is better than NUIGMech1.0 at some conditions (e.g., hightemperature regime $>1400 \mathrm{~K})$ such as in Figures 2(h), 3(b), 4(f) and 4(h).

Table 3. Evaluated coefficients for correlation of the simulated IDTs for methane + ethylene mixtures.

\begin{tabular}{|c|c|c|}
\hline \multirow{2}{*}{$\begin{array}{c}\mathbf{2 5} \leq \boldsymbol{\varphi} \leq \mathbf{2 . 0} \\
\mathbf{7 5} \leq \text { Dilution } \leq \mathbf{9 5 \%}\end{array}$} & \multicolumn{2}{|c|}{$\mathbf{2 0} \leq \boldsymbol{p}_{\mathbf{5 , c}} \leq \mathbf{5 0} / \mathbf{a t m}$} \\
\cline { 2 - 3 } $\mathbf{A}$ & $\mathbf{8 0 0} \leq \boldsymbol{T}_{\mathbf{5 , c}}<\mathbf{1 2 0 0} / \mathbf{K}$ & $\mathbf{1 2 0 0} \leq \boldsymbol{T}_{\mathbf{5 , c}} \leq \mathbf{2 0 0 0} / \mathbf{K}$ \\
\hline $\mathbf{B}$ & $-8.335 \pm 0.021$ & $-9.901 \pm 0.0236$ \\
\hline $\mathbf{C}$ [methane] & $-0.214 \pm 0.0018$ & $18356.2 \pm 63.216$ \\
\hline $\mathbf{D}$ [ethylene] & $-0.598 \pm 0.0019$ & $1.047 \pm 0.0053$ \\
\hline $\mathbf{E}$ & $-0.1362 \pm 0.0023$ & $-1.1196 \pm 0.0054$ \\
\hline $\mathbf{F}$ & $0.0746 \pm 0.004$ & $-1.2955 \pm 0.0046$ \\
\hline $\mathbf{R}^{\mathbf{2}}$ & 0.991 & $0.684 \pm 0.0069$ \\
\hline $\boldsymbol{\chi}^{\mathbf{2}}$ & $2.54 \mathrm{E}-04$ & 0.976 \\
\hline
\end{tabular}

Table 4. Evaluated coefficients for correlation of the simulated IDTs for methane + ethane mixtures.

\begin{tabular}{|c|c|c|c|}
\hline $\mathbf{0 . 2 5} \leq \boldsymbol{\varphi} \leq \mathbf{2 . 0}$ & $\mathbf{2 0} \leq \boldsymbol{p}_{\mathbf{5 , c}} \leq \mathbf{5 0} / \mathbf{a t m}$ & $\mathbf{1} \leq \boldsymbol{p}_{\mathbf{5 , c}} \leq \mathbf{1 5} / \mathbf{a t m}$ & $\mathbf{1 5}<\boldsymbol{p}_{\mathbf{5 , c}} \leq \mathbf{5 0} / \mathbf{a t m}$ \\
\cline { 2 - 4 } $\mathbf{7 5} \leq \mathbf{D i l u t i o n} \leq \mathbf{9 5 \%}$ & $\mathbf{8 0 0} \leq \boldsymbol{T}_{\mathbf{5 , c}}<\mathbf{1 2 0 0} / \mathbf{K}$ & \multicolumn{2}{|c|}{$\mathbf{1 2 0 0} \leq \boldsymbol{T}_{\mathbf{5 , c}}<\mathbf{2 0 0 0} / \mathbf{K}$} \\
\hline $\mathbf{A}$ & $-9.783 \pm 0.0151$ & $-9.101 \pm 0.033$ & $-9.949 \pm 0.0264$ \\
\hline $\mathbf{B}$ & $19718.499 \pm 26.840$ & $19258.657 \pm 97.04$ & $19458.945 \pm 72.877$ \\
\hline $\mathbf{C}[$ methane] & $-0.1653 \pm 9.26 \mathrm{E}-04$ & $1.439 \pm 0.008$ & $0.7469 \pm 0.0042$ \\
\hline $\mathbf{D}[$ ethane] & $-0.4759 \pm 0.001$ & $-0.2413 \pm 0.009$ & $-0.717 \pm 0.0045$ \\
\hline $\mathbf{E}$ & $-0.067 \pm 0.0012$ & $-2.111 \pm 0.0107$ & $-1.129 \pm 0.0044$ \\
\hline $\mathbf{F}$ & $-0.1378 \pm 0.002$ & $0.3386 \pm 0.0054$ & $0.4771 \pm 0.007$ \\
\hline $\mathbf{R}^{\mathbf{2}}$ & 0.998 & 0.974 & 0.973 \\
\hline$\chi^{\mathbf{2}}$ & $3.74 \mathrm{E}-04$ & $4.32 \mathrm{E}-09$ & $2.34 \mathrm{E}-10$ \\
\hline
\end{tabular}

Table 5. Evaluated coefficients for correlation of the simulated IDTs for ethane + ethylene mixtures.

\begin{tabular}{|c|c|c|c|}
\hline $\mathbf{0 . 2 5} \leq \boldsymbol{\varphi} \leq \mathbf{2 . 0}$ & $\mathbf{2 0} \leq \boldsymbol{p}_{\mathbf{5 , c}} \leq \mathbf{5 0} / \mathbf{a t m}$ & $\mathbf{1} \leq \boldsymbol{p}_{\mathbf{5 , c}} \leq \mathbf{1 5} / \mathbf{a t m}$ & $\mathbf{1 5}<\boldsymbol{p}_{\mathbf{5 , c}} \leq \mathbf{5 0} / \mathbf{a t m}$ \\
\cline { 2 - 4 } $\mathbf{7 5} \leq$ Dilution $\leq \mathbf{9 5} \%$ & $\mathbf{8 0 0} \leq \boldsymbol{T}_{\mathbf{5 , c}}<\mathbf{1 2 0 0} / \mathbf{K}$ & \multicolumn{2}{|c|}{$\mathbf{1 2 0 0} \leq \boldsymbol{T}_{\mathbf{5 , c}}<\mathbf{2 0 0 0} / \mathbf{K}$} \\
\hline $\mathbf{A}$ & $-9.827 \pm 0.0261$ & $-8.6581 \pm 0.0209$ & $-12.118 \pm 0.0298$ \\
\hline $\mathbf{B}$ & $19125.037 \pm 46.261$ & $15455.624 \pm 62.281$ & $23088.771 \pm 86.772$ \\
\hline $\mathbf{C}$ [ethylene] & $-0.466 \pm 0.0017$ & $-0.0348 \pm 0.004$ & $-0.2374 \pm 0.0027$ \\
\hline $\mathbf{D}[$ ethane] & $-0.2555 \pm 0.0018$ & $0.4395 \pm 0.0044$ & $0.0316 \pm 0.0029$ \\
\hline $\mathbf{E}$ & $-0.0496 \pm 0.0021$ & $-1.2105 \pm 0.0057$ & $-0.4924 \pm 0.0034$ \\
\hline $\mathbf{F}$ & $-0.08497 \pm 0.0037$ & $0.2072 \pm 0.0045$ & $0.41 \pm 0.0056$ \\
\hline $\mathbf{R}^{\mathbf{2}}$ & 0.992 & 0.977 & 0.976 \\
\hline$\chi^{\mathbf{2}}$ & $5.19 \mathrm{E}-04$ & $1.12 \mathrm{E}-10$ & $1.19 \mathrm{E}-11$ \\
\hline
\end{tabular}

Table 6. Performance of the methane/ethylene correlations versus the experimental data shown in Fig. 2.

\begin{tabular}{|c|c|c|}
\hline Experimental data set & $\overline{\boldsymbol{\delta}}_{\text {corr-exp }}(\boldsymbol{\%})$ & $\overline{\boldsymbol{\sigma}}_{\text {corr-exp }}(\boldsymbol{\%})$ \\
\hline P5C1 & 47.5 & 22.1 \\
\hline P5C2 & 28.3 & 7.5 \\
\hline P5C3 & 29.0 & 15.0 \\
\hline P5C4 & 33.8 & 22.8 \\
\hline P5C5 & 38.4 & 5.9 \\
\hline
\end{tabular}




\begin{tabular}{|c|c|c|}
\hline P5C6 & 26.0 & 17.0 \\
\hline P5C7 & 9.9 & 9.6 \\
\hline P5C8 & 19.8 & 9.1 \\
\hline P5C9 & 131.0 & 56.4 \\
\hline
\end{tabular}

Table 7. Performance of the methane/ethane correlations versus the experimental data shown in Fig. 3.

\begin{tabular}{|c|c|c|}
\hline Experimental data set & $\overline{\boldsymbol{\delta}}_{\text {corr-exp }}(\boldsymbol{\%})$ & $\overline{\boldsymbol{\sigma}}_{\text {corr-exp }}(\boldsymbol{\%})$ \\
\hline P6C1 & 34.1 & 15.5 \\
\hline P6C2 & 2.1 & 0.8 \\
\hline P6C3 & 18.5 & 7.1 \\
\hline P6C4 & 49.1 & 47.2 \\
\hline P6C5 & 40.8 & 36.3 \\
\hline P6C6 & 30.7 & 10.1 \\
\hline P6C7 & 68.1 & 8.3 \\
\hline P6C8 & 24.5 & 26.0 \\
\hline P6C9 & 45.3 & 3.8 \\
\hline
\end{tabular}

Table 8. Performance of the ethane/ethylene correlations versus the experimental data shown in Fig. 4.

\begin{tabular}{|c|c|c|}
\hline Experimental data set & $\overline{\boldsymbol{\delta}}_{\text {corr-exp }}(\boldsymbol{\%})$ & $\overline{\boldsymbol{\sigma}}_{\text {corr-exp }}(\boldsymbol{\%})$ \\
\hline P8C1 & 39.5 & 11.8 \\
\hline P8C2 & 28.8 & 3.4 \\
\hline P8C3 & 80.6 & 92.9 \\
\hline P8C4 & 36.5 & 37.3 \\
\hline P8C5 & 36.8 & 4.0 \\
\hline P8C6 & 24.9 & 33.9 \\
\hline P8C7 & 24.7 & 11.9 \\
\hline P8C8 & 74.6 & 92.5 \\
\hline P8C9 & 9.9 & 11.8 \\
\hline
\end{tabular}




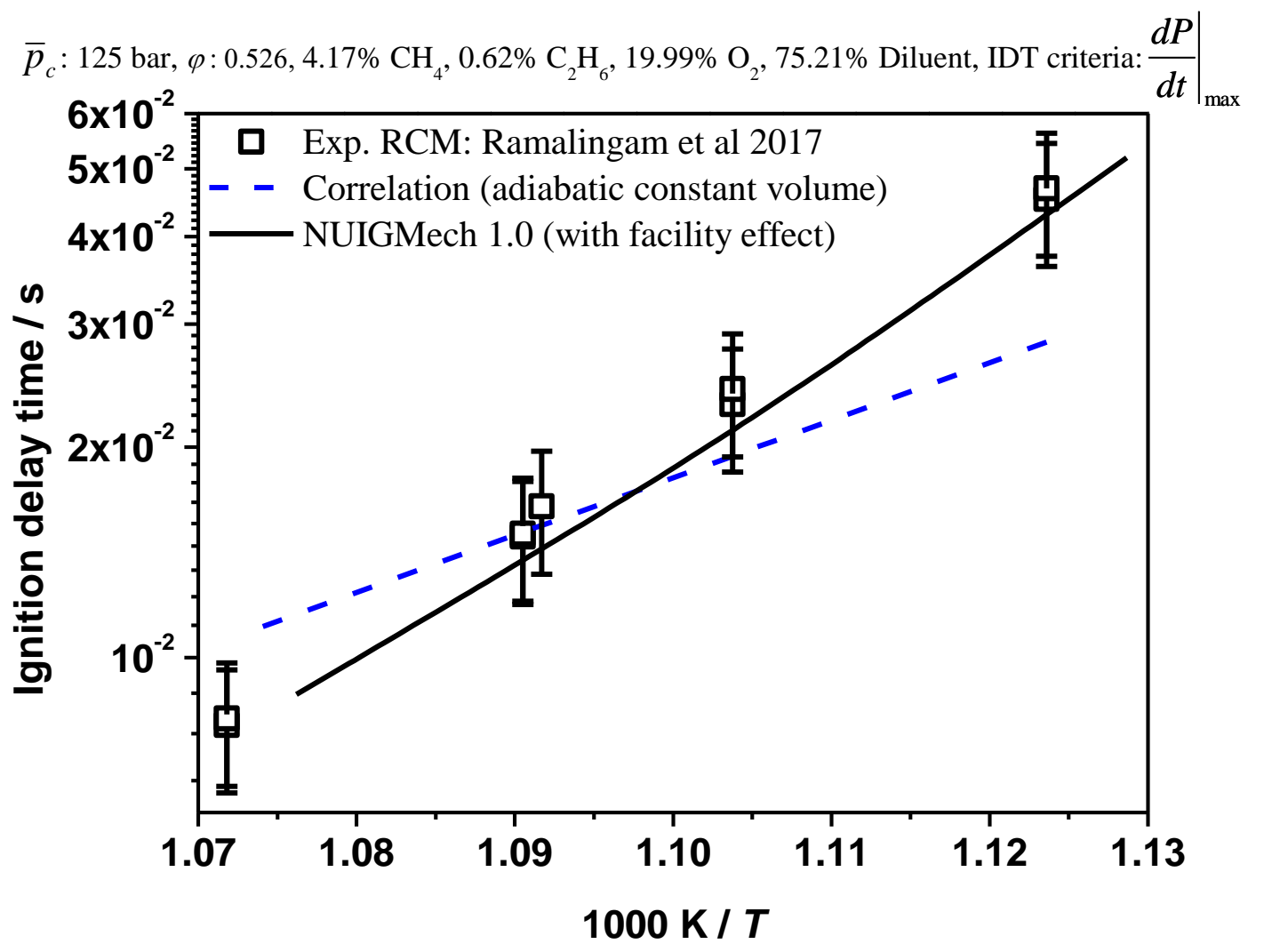

Figure 11. Performance of the derived correlation under an overpressure (> 50 bar) condition ${ }^{10}$.

\section{Conclusions}

To create a comprehensive IDT database, a detail experimental and simulation study of the IDT characteristics of binary blended $\mathrm{C}_{1}-\mathrm{C}_{2}$ alkane/alkene fuels including methane/ethylene, methane/ethane, and ethane/ethylene combinations over a wide range of temperature, pressure, equivalence ratio, binary combination, and dilution was performed. An extensive literature review was conducted, and available data, especially for methane/ethane blends were extracted to be used in the simulations. The experimental tests were designed using the Taguchi matrix $\left(\mathrm{L}_{9}\right)$. Nine data sets including 160 data points for methane + ethylene ( $p_{\mathrm{C}}: 1,20$ and 40 bar; $\varphi: 0.5,1.0$, and 2.0 ; dilution: 75, 85, and 90\%) and nine data sets including 140 data points for ethane + ethylene ( $p_{\mathrm{C}}: 1,20$, and 40 bar; $\varphi: 0.5,1.0$, and 2.0 ; dilution: 75, 85, and 90\%) were recorded using L/HPST and RCM facilities at $\mathrm{C}^{3}$-NUIG and PCFC-RWTH Aachen University. The experimental data presented here provides a new insight into the oxidation of alkane/alkene blended fuel mixtures. These findings are technologically important in terms of safety and the design of new lowemission and size-efficient combustion systems.

The individual effects of the studied parameters (alkane ratio, dilution, equivalence ratio, and dilution) on the IDTs have been considered in detail. The results showed that most parameters do not have a monotonic effect on mixture reactivity over the entire temperature range (800-2100 K), in that the reactivity of mixtures in certain temperature ranges can be very sensitive to the studied parameters, while this sensitivity can be low over other temperature ranges. Interestingly, it was shown that increasing the alkanes concentration in the alkane + alkene blends at 1 bar, $\varphi: 0.5$ and dilution of $75 \%$ has a Gaussian 
distribution with temperature around $1200 \mathrm{~K}$. However, increasing the pressure or dilution percent has a minimum effect on the blends reactivity at $1200 \mathrm{~K}$ and $1100 \mathrm{~K}$, respectively.

Furthermore, the performances of NUIGMech1.0, in addition to several derived correlations for the blended fuels, were evaluated using all of the available and measured experimental IDT data. The results showed that NUIGMech1.0 could acceptably predict the measured IDTs. Moreover, the results showed that the derived correlations based on NUIGMech1.0 for the studied blended fuel mixtures could satisfactorily reproduce the experimental IDT data within the studied range. This can be a very versatile rule-of-thumb tool to use in predicting the IDT characteristics of the fuel blends studied.

\section{Acknowledgements}

The authors would like to express their gratitude to Shell Research Ltd. and Science Foundation Ireland (SFI) for funding via project numbers 15/IA/3177 and 16/SP/3829. The authors from PCFC, RWTH Aachen University, would like to recognize the funding support from the German Research Foundation (Deutsche Forschungsgemeinschaft, DFG) through the project number - 322460823 (HE7599/2-1).

\section{Supplementary files}

All supplementary files are attached to the online version of the article.

1- The Supporting Information file (.pdf); including all referred items and plots in the manuscript.

2- The Supplementary files (.zip); including all raw data such as datasheets and oscilloscopes [HandyScope for HPST data] voltage and pressure traces.

\section{References}

1. Shao, J. K.; Davidson, D. F.; Hanson, R. K., A shock tube study of ignition delay times in diluted methane, ethylene, propene and their blends at elevated pressures. Fuel 2018, 225, 370-380.

2. Aul, C. J.; Metcalfe, W. K.; Burke, S. M.; Curran, H. J.; Petersen, E. L., Ignition and kinetic modeling of methane and ethane fuel blends with oxygen: A design of experiments approach. Combust. Flame 2013, 160, (7), 1153-1167.

3. Beerer, D. J.; McDonell, V. G., An experimental and kinetic study of alkane autoignition at high pressures and intermediate temperatures. Proc. Combust. Inst. 2011, 33, 301-307.

4. de Vries, J.; Petersen, E. L., Autoignition of methane-based fuel blends under gas turbine conditions. Proc. Combust. Inst. 2007, 31, 3163-3171.

5. Burke, S. M.; Metcalfe, W.; Herbinet, O.; Battin-Leclerc, F.; Haas, F. M.; Santner, J.; Dryer, F. L.; Curran, H. J., An experimental and modeling study of propene oxidation. Part 1: Speciation measurements in jet-stirred and flow reactors. Combust. Flame 2014, 161, (11), 2765-2784.

6. Lamoureux, N.; Paillard, C. E., Natural gas ignition delay times behind reflected shock waves: Application to modelling and safety. Shock Waves 2003, 13, (1), 57-68.

7. Huang, J.; Bushe, W. K., Experimental and kinetic study of auto-ignition in methane/ethane/air and methane/propane/air mixtures under engine-relevant conditions. Combust. Flame 2006, 144, 74-88.

8. $\quad$ Petersen, E. L.; Hall, J. M.; Smith, S. D.; de Vries, J.; Amadio, A. R.; Crofton, M. W., Ignition of lean methane-based fuel blends at gas turbine pressures. J. Eng. Gas Turb. Power 2007, 129, (4), 937-944.

9. Gersen, S.; Mokhov, A. V.; Darmeveil, J. H.; Levinsky, H. B.; Glarborg, P., Ignition-promoting effect of $\mathrm{NO}_{2}$ on methane, ethane and methane/ethane mixtures in a rapid compression machine. Proc. Combust. Inst. 2011, 33, 433-440.

10. Ramalingam, A.; Zhang, K. W.; Dhongde, A.; Virnich, L.; Sankhla, H.; Curran, H.; Heufer, A., An RCM experimental and modeling study on $\mathrm{CH}_{4}$ and $\mathrm{CH}_{4} / \mathrm{C}_{2} \mathrm{H}_{6}$ oxidation at pressures up to 160 bar. Fuel 2017, 206, 325333. 
11. Herzler, J.; Naumann, C., Shock-tube study of the ignition of methane/ethane/hydrogen mixtures with hydrogen contents from $0 \%$ to $100 \%$ at different pressures. Proc. Combust. Inst. 2009, 32, 213-220.

12. $\quad$ Ross, P. J., Taguchi Techniques for Quality Engineering. McGraw-Hill: New York, 1988.

13. Baigmohammadi, M.; Patel, V.; Martinez, S.; Panigrahy, S.; Ramalingam, A.; Burke, U.; Somers, K. P.; Heufer, K. A.; Pekalski, A.; Curran, H. J., A Comprehensive Experimental and Simulation Study of Ignition Delay Time Characteristics of Single Fuel $\mathrm{C}_{1}-\mathrm{C}_{2}$ Hydrocarbons over a Wide Range of Temperatures, Pressures, Equivalence Ratios, and Dilutions. Energ. Fuel 2020, 34, (3), 3755-3771.

14. Burke, U.; Somers, K. P.; O'Toole, P.; Zinner, C. M.; Marquet, N.; Bourque, G.; Petersen, E. L.; Metcalfe, W. K.; Serinyel, Z.; Curran, H. J., An ignition delay and kinetic modeling study of methane, dimethyl ether, and their mixtures at high pressures. Combust. Flame 2015, 162, (2), 315-330.

15. Donohoe, N.; Heufer, K. A.; Aul, C. J.; Petersen, E. L.; Bourque, G.; Gordon, R.; Curran, H. J., Influence of steam dilution on the ignition of hydrogen, syngas and natural gas blends at elevated pressures. Combust. Flame 2015, 162, (4), 1126-1135.

16. Gallagher, S. M.; Curran, H. J.; Metcalfe, W. K.; Healy, D.; Simmie, J. M.; Bourque, G., A rapid compression machine study of the oxidation of propane in the negative temperature coefficient regime. Combust. Flame 2008, 153, (1-2), 316-333.

17. Healy, D.; Curran, H. J.; Dooley, S.; Simmie, J. M.; Kalitan, D. M.; Petersen, E. L.; Bourque, G., Methane/propane mixture oxidation at high pressures and at high, intermediate and low temperatures. Combust. Flame 2008, 155, (3), 451-461.

18. Healy, D.; Curran, H. J.; Simmie, J. M.; Kalitan, D. M.; Zinner, C. M.; Barrett, A. B.; Petersen, E. L.; Bourque, G., Methane/ethane/propane mixture oxidation at high pressures and at high, intermediate and low temperatures. Combust. Flame 2008, 155, (3), 441-448.

19. Healy, D.; Kalitan, D. M.; Aul, C. J.; Petersen, E. L.; Bourque, G.; Curran, H. J., Oxidation of $\mathrm{C}_{1}-\mathrm{C}_{5} \mathrm{Alkane}$ Quintenary Natural Gas Mixtures at High Pressures. Energ. Fuel 2010, 24, 1521-1528.

20. Petersen, E. L.; Rickard, M. J. A.; Crofton, M. W.; Abbey, E. D.; Traum, M. J.; Kalitan, D. M., A facility for gas- and condensed-phase measurements behind shock waves. Meas. Sci. Technol. 2005, 16, (9), $1716-1729$.

21. Weber, B. W.; Sung, C. J.; Renfro, M. W., On the uncertainty of temperature estimation in a rapid compression machine. Combust. Flame 2015, 162, (6), 2518-2528.

22. Goldsborough, S. S.; Hochgreb, S.; Vanhove, G.; Wooldridge, M. S.; Curran, H. J.; Sung, C. J., Advances in rapid compression machine studies of low- and intermediate-temperature autoignition phenomena. Prog. Energ. Combust. 2017, 63, 1-78.

23. Sung, C. J.; Curran, H. J., Using rapid compression machines for chemical kinetics studies. Prog. Energ. Combust. 2014, 44, 1-18.

24. Goodwin, D. G.; Speth, R. L.; Moffat, H. K.; Weber, B. W. Cantera: An object-oriented software toolkit for chemical kinetics, thermodynamics, and transport processes. https://www.cantera.org

25. Reaction-Design CHEMKIN-PRO 18.2, San Diego, 2013.

26. Dames, E. E.; Rosen, A. S.; Weber, B. W.; Gao, C. W.; Sung, C. J.; Green, W. H., A detailed combined experimental and theoretical study on dimethyl ether/propane blended oxidation. Combust. Flame 2016, 168, 310330.

27. Gururajan, V.; Egolfopoulos, F. N., Direct sensitivity analysis for ignition delay times. Combust. Flame 2019, 209, 478-480.

28. Origin(Pro), "Version 8.5", OriginLab Corporation: Northampton, MA, USA. 